\title{
A Global Projection Model for Euro Area Large Economies
}




\section{A Global Projection Model for Euro Area Large Economies}

Zoltan Jakab, Pavel Lukyantsau, Shengzu Wang 


\title{
IMF Working Paper
}

European Department and Research Department

\section{A Global Projection Model for Euro Area Large Economies}

Prepared by Zoltan Jakab, Pavel Lukyantsau and Shengzu Wang

Authorized for distribution by Kenneth Kang and Douglas Laxton

March 2015

\section{This Working Paper should not be reported as representing the views of the IMF.} The views expressed in this Working Paper are those of the author(s) and do not necessarily represent those of the IMF or IMF policy. Working Papers describe research in progress by the author(s) and are published to elicit comments and to further debate.

\begin{abstract}
The GPM project is designed to improve the toolkit for studying both own-country and crosscountry linkages. This paper creates a special version of GPM that includes the four largest Euro Area (EA) countries. The EA countries are more vulnerable to domestic and external demand shocks because adjustments in the real exchange rate between EA countries occur more gradually through inflation differentials. Spillovers from tight credit conditions in each EA country are limited by direct trade channels and small confidence spillovers, but we also consider scenarios where banks in all EU countries tighten credit conditions simultaneously.
\end{abstract}

JEL Classification Numbers: C53, F41, O52

Keywords: Global projection model; Euro area; Forecasting

Author's E-Mail Address: ZJakab@imf.org; PLukyantsau@,imf.org; Swang2@,imf.org 
Contents Page

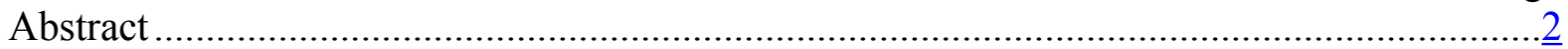

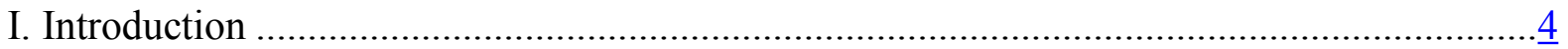

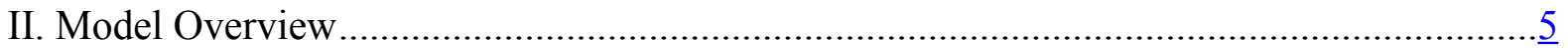

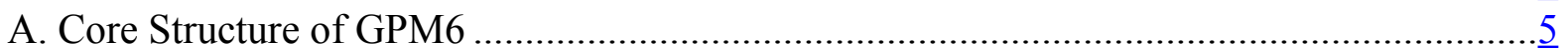

B. Introducing Large EA Countries into the EA4 GPM ....................................................

III. Model Properties, Parameterization and Simulation results ............................................. 9

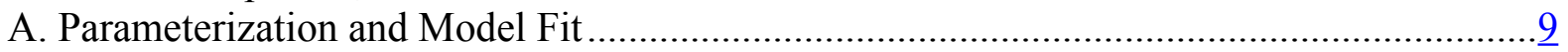

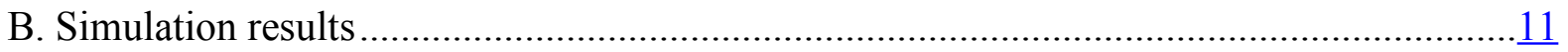

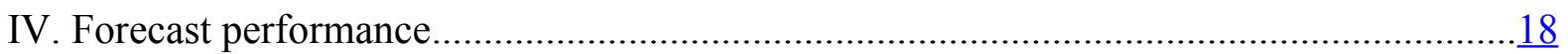

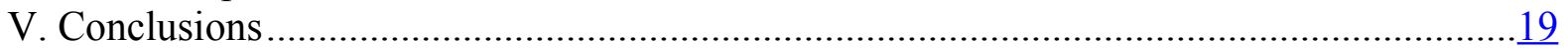

Appendix I. Out-of-sample forecast performance (RMSEs) ………………………..........22

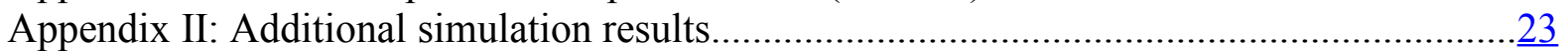

Appendix III. : Euro area forecasts from the EA4 GPM ..................................................28

Appendix IV: Modified Notation in Country Blocks of the EA4 GPM ..............................29

Appendix V. Calibration of Spillover Coefficients …………..............................................

Figures

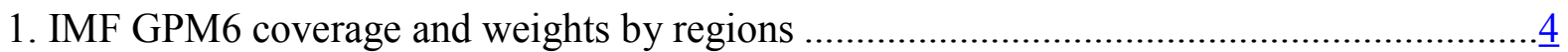

2. Nonlinear Effects of Output Gap on Core Inflation........................................................

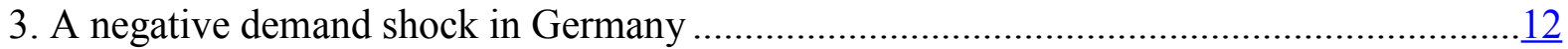

4. A common negative demand shock in the euro area ......................................................13

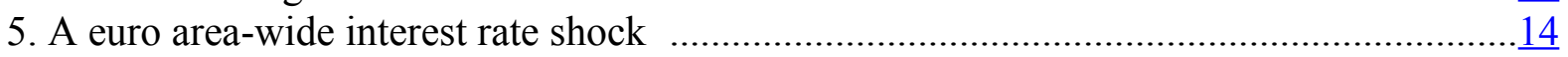

6. A bank lending tightening shock in Germany .............................................................

7. A common bank lending tightening shock ………....................................................

8. Counterfactual exercise of looser bank lending standards after 2007Q4 ...........................16

9. Counterfactual exercise of looser bank lending standards after 2011Q3 .................17

\section{Tables}

1. Calibrated and estimated country-level parameters ..........................................................

2. Spillover coefficients across countries and regions ............................................................11

3a. Selected Euro Area Countries: Growth Forecasts, 2014-16 ...........................................18

3b. Selected Euro Area Countries: Inflation (Headline), 2014-16 ........................................18 


\section{INTRODUCTION ${ }^{1}$}

The IMF's Global Projection Model (GPM) is a general equilibrium model that incorporates a number of country or regional reduced-form macro model blocks that are interconnected through a number of economic and financial linkages. It allows users to produce a coherent outlook for the world economy, and to conduct policy analysis in a comprehensive manner.

This paper extends the existing six-region GPM framework (GPM6) by introducing additional blocks for four large euro area (EA) economies, namely Germany, France, Italy, and Spain. The current EA block (15.1 percent of world GDP) is therefore decomposed into five blocks, with remaining EA members grouped as the rest of EA. This is motivated by the significant weights of large EA member states, and by their impact on the EA economy and its policies. This represents an effort to introduce a "bottom-up" aspect of forecasting that complements the existing GPM framework, which produces a forecast for the euro area as a whole (the "top-down" approach").

Figure 1. IMF GPM6 coverage and weights by regions

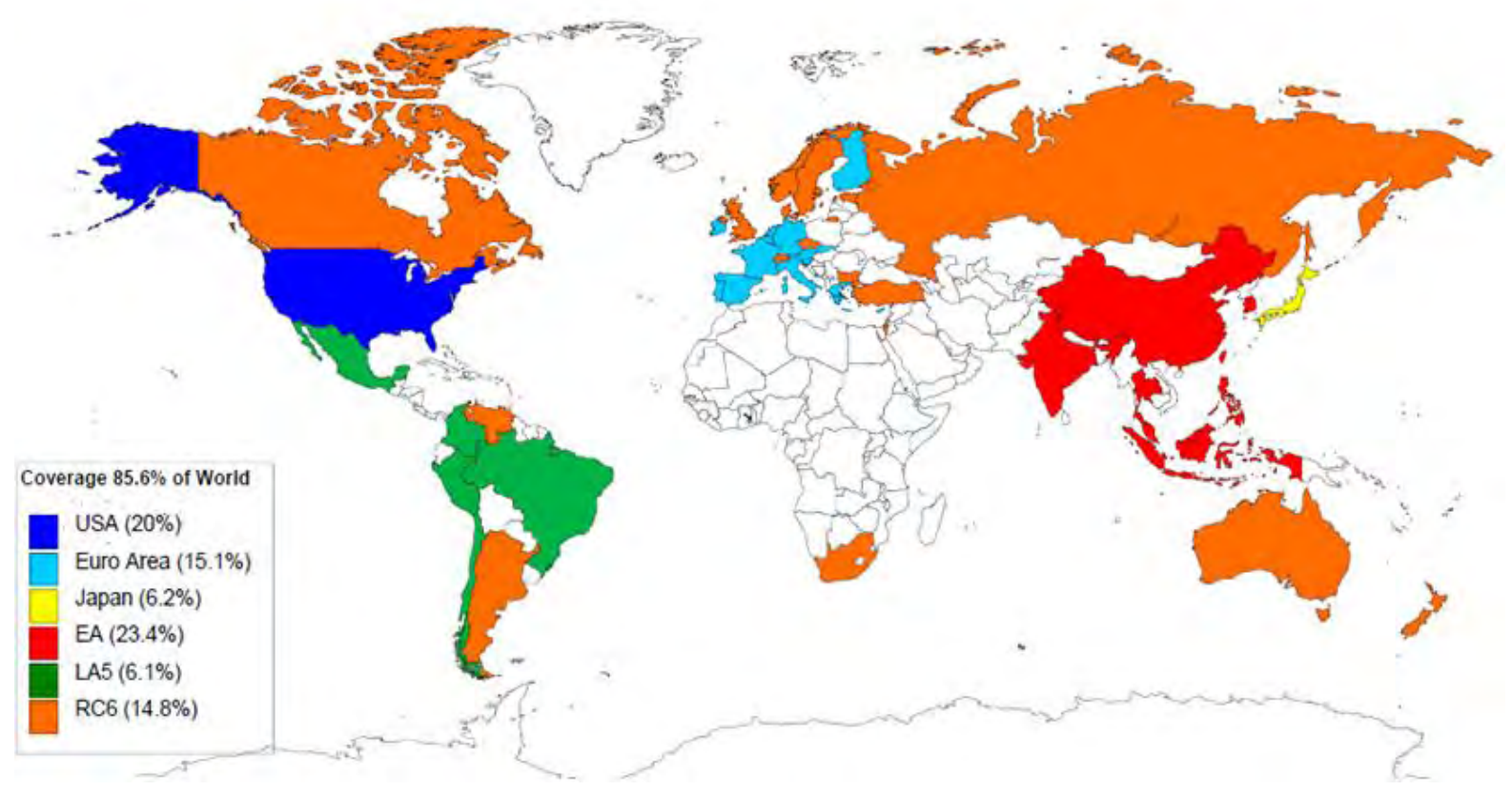

Similar to other variants of GPM used by the IMF, the modeling strategy applied here is to take advantage of and balance the use of two common classes of macro models: fully structural dynamic stochastic general equilibrium (DSGE) models that are theoretically sound (but that in some cases lack empirical consistency), and multivariate time-series models that usually fit the data better. In this context, the modified GPM (EA4 GPM)

\footnotetext{
${ }^{1}$ The authors thank to Douglas Laxton, Petya Koeva Brooks, Kenneth Kang, Michael Kumhof, James John, as well as seminar participants from European and Research departments of the IMF, for their helpful comments and suggestions. Xiaobo Shao provided excellent research assistance. All remaining errors are the authors' own.
} 
inherits the core macro structure of GPM6, including the New-Keynesian Phillips Curve, IS Curve and monetary policy reaction function, which ensures theoretical consistency and desirable model properties. It also features a system of simultaneous equations for trade and financial linkages using estimated parameters from VAR or other time-series models, with an effort to improve the consistency of the forecast by embracing more country level information.

The current paper differs from other work on the euro area using the GPM framework in the following ways. First, the paper breaks down the existing EA block into five separate blocks representing Germany, France, Italy and Spain. This allows country- specific shocks (e.g. demand shocks in Germany) to generate spillovers and feedbacks within the euro area, which can be used for alternative scenarios and risk assessments. ${ }^{2}$ Second, changes have been made to monetary policies to take account of the currency union, and of nonlinearities like the zero lower bound on nominal interest rates and a flattened Philips Curve.

The rest of the paper is organized as follows: Section II provides a brief introduction of the original GPM, and of changes made in the modified EA4 GPM. Section III discusses model properties including parameterization and impulse-response functions. Section IV presents a summary of out-of-sample forecasts for the euro area underpinning the IMF WEO update of July 2014. Section V concludes. The Appendices present additional impulse-responses and detailed model notation.

\section{Model OVERVIEW}

This section starts with an overview of GPM6 and its key equations, ${ }^{3}$ followed by a discussion of how to introduce large EA economies into the model. Our focus is on the equations for aggregate demand, monetary policy, and inflation/exchange rate, given that these are the equations that will need to be adapted to capture the feature of EA economies.

\section{A. Core Structure of GPM6}

GPM6 contains a set of behavioral equations for each of its six regional blocks, representing the structure of the economy. These equations describe the evolution of output, inflation, interest rates, exchange rates, and commodity prices. Most variables are specified in terms of deviations from their steady-state equilibrium values, in some cases supplemented by leads and lags for the dynamic adjustment process. There is also some notable distinction between the G3 economies (US, EA, and Japan) and other economies in the model. For example, output in G3 economies can be affected by changes in domestic financial conditions, while

\footnotetext{
${ }^{2}$ For modeling purpose, shocks from outside of the euro area are imported from GPM6 and taken as given to ensure solvability and convergence.

${ }^{3}$ See Carabenciov and others (2013) and Blagrave and others (2013) for a detailed description of GPM6 and its variants.
} 
this channel is absent in non-G3 economies (though foreign financial shocks do affect nonG3 growth). The key macroeconomic variables are modeled through the following equations.

First, aggregate demand is represented by the New Keynesian IS curve. In this setup, the output gap $\left(y_{t}\right)$ in each G3 economy is assumed to be affected by the real interest rate gap (defined as deviations of the lagged real interest rate $R R_{t-1}$ from its steady state value $\overline{R R}_{t-1}$ ), the real effective exchange rate gap (defined as deviations of the moving average real effective exchange rate $\sum_{i=t-1}^{t-4}\left(R E E R_{i}\right)$ from its moving average equilibrium value $\sum_{i=t-1}^{t-4}\left(\overline{R E E R}_{i}\right)$, where an increase in the real exchange rate represents a depreciation), foreign demand $\left(\Omega_{t}\right)$, financial conditions $\left(\theta_{t}\right.$, known as "bank lending tightening", or BLT), commodity prices $\left(\kappa_{t}\right)$, two disturbance terms $\left(\varepsilon_{t}^{y y}\right.$ and $\left.\varepsilon_{t}^{y}\right)$, as well as leads and lags of output:

$$
\begin{gathered}
y_{t}=\beta_{1} y_{t-1}+\beta_{2} y_{t+1}-\beta_{3}\left(R R_{t-1}-\overline{R R}_{t-1}\right)+\beta_{4} \Sigma_{i=t-1}^{t-4}\left(R E E R_{i}-\overline{R E E R}_{i}\right) / 4+ \\
\Omega_{t}+\theta_{t}+\kappa_{t}+\beta_{\text {factres }} \varepsilon_{t}^{y y}++\beta_{4 f a c t} \varepsilon_{t}^{y}
\end{gathered}
$$

Next, the inflation process $\left(\pi_{t}\right)$ is assumed to follow a typical New Keynesian Phillips Curve. More specifically, core inflation is affected by the lagged output gap, the real effective exchange rate gap as in equation (1), and a disturbance term $\left(\varepsilon_{t}^{\pi}\right) .{ }^{4}$ In addition, backward- and forward-looking inflation terms are introduced to better capture inflation dynamics, with $\lambda_{1 x}$ capturing the underlying expectations-formation mechanism of core inflation:

$$
\pi_{t}=\lambda_{1 x} \pi_{t+4}+\left(1-\lambda_{1}\right) \pi_{t-1}+\lambda_{2 x} y_{t-1}+\lambda_{3 x} \Sigma_{i=t-1}^{t-4}\left(R E E R_{i}-\overline{R E E R}_{i}\right) / 4+\varepsilon_{t}^{\pi}
$$

The monetary policy framework is one of inflation targeting. Specifically, the monetary authority uses the nominal short-term interest rate to ensure that inflation reverts to its target rate over time. Hence the monetary policy reaction function is specified using an inflationforecast-based rule with an interest-rate smoothing component:

$$
R S_{t}=\left(1-\gamma_{1}\right)\left[\overline{R R}_{t}+\pi_{t+4}^{e}+\gamma_{2}\left(\pi_{t+4}^{e}-\pi_{\text {target }}\right)+\gamma_{4} y_{t}\right]+\gamma_{1} R S_{t-1}+\varepsilon_{t}^{R S}
$$

where $R S_{t}$ is the short-term nominal interest rate, $\overline{R R}_{t}$ is the equilibrium short-term real interest rate, $\pi_{t+4}^{e}$ is expected one-year-ahead inflation, $\pi_{\text {target }}$ is the inflation target, and $\varepsilon_{t}^{R S}$ is a disturbance term. ${ }^{5}$

Regarding the exchange rate, it is assumed that the real interest rate parity links real exchange rate movements to domestic and foreign real interest rate differentials. For all

\footnotetext{
${ }^{4}$ Spillovers from foreign demand occur via foreign output gaps, and shocks to foreign $\varepsilon_{t}^{y y}$ terms. This structure of headline inflation including food prices can be found in Carabenciov and others (2013).

${ }^{5}$ For a discussion of Inflation-Forecast-Based (IFB) rules, see Laxton, Rose, and Tetlow (1993) and Amano, Coletti, and Macklem (1998). In addition, when the policy rate hits the zero-lower-bound, the responses of inflation to output and policy rates may become non-linear, see discussion in next section.
} 
countries in GPM6, the expected change in the real exchange rate is derived from the forward solution of the model, which also ensures that real interest rate differentials are consistent with expected real exchange rate changes (details for the real exchange rate of the euro area are discussed in the next section). This hybrid approach in modeling real exchange rate expectations allows us to better capture the dynamics of empirical exchange rates adjustments. The real interest parity condition is presented as:

$$
R R_{t}=R R_{t}^{U S}+4\left(L Z_{t+1}^{e}-L Z_{t}\right)+\overline{R R}_{t}-\overline{R R}_{t}^{U S}+\varepsilon_{t}^{U I P}
$$

where $L Z_{t}$ is the real bilateral exchange rate against the US dollar (expressed as domestic currency per unit of foreign currency), $L Z_{t+1}^{e}$ is a blend of the model-consistent expectation of $L Z$ and a lag, where $L Z_{t+1}^{e}=\varphi L Z_{t+1}+(1-\varphi) L Z_{t-1}$, and $\varepsilon_{t}^{U I P}$ is a disturbance term. ${ }^{6}$

\section{B. Introducing Large EA Countries into the EA4 GPM}

This section describes the modeling changes in the EA4 GPM. Four large EA countries are split out from the EA block of GPM6. These are Germany (GR), France (FR), Italy (IT), and Spain (SP), and the remaining ones are grouped as the rest of the EA (EX). Each country block has a similar economic structure, with the core equations specified in the previous section, though country-specific parameters apply (see the next section and Appendix Table 1 for parameter values). ${ }^{7}$ The remainder of this section presents the key features of the new model relative to the benchmark GPM6.

One of the major changes to the EA block is that more granularities are introduced into the model, so that the four economies above can behave differently if necessary. For example, country-level BLT is used to represent the lending conditions of each economy, and account for heterogeneity in financial markets:

$$
B L T_{i, t}=\overline{B L T}_{i, t}-\kappa_{i} y_{i, t+4}+\varepsilon_{i, t}
$$

where $B L T_{i, t}$ is the country level bank lending tightening (an increase of the index means tightening), $y_{i, t+4}$ is the one-year ahead model-consistent expectation of the country-specific output gap, and $\varepsilon_{i, t}$ is a disturbance term.

\footnotetext{
${ }^{6}$ Equation (4) is a version of (real) uncovered interest parity (or UIP). The real interest rate difference between any country $i$ and the US is equal to the difference between the log of the real exchange rate of currency $i$ relative to the US dollar and its expected value in the following quarter plus the difference in the equilibrium real interest rates. The difference in the equilibrium real interest rates is equivalent to the equilibrium risk premium. Thus, if the real interest rate in country $i$ is greater than that in the US, this would be a reflection of one of two possibilities or a combination of the two-either the currency i real exchange rate is expected to depreciate over the coming period $\left(Z^{e}\right.$ is higher than $Z_{t}$ ), or the equilibrium real interest rates in the two countries differ because of a risk premium on yields of country $i$ assets denominated in its currency. ${ }^{7}$ The modified model still represents the whole euro area as one single block, as in the benchmark model (GPM6). For forecasting purpose, shocks from the rest of world are treated as exogenous, and the rest of EA is treated as a residual derived from the forecast of the EA block and its four large economies.
} 
Aggregate demand and inflation are modeled as in Eq. (1) and (2) of GPM6, respectively, with the exception that short-term effects of shocks to output, real effective exchange rates and commodity prices are also made country-specific, with spillovers to others in the EA. ${ }^{8}$

As EA is a currency union, the modeling of monetary policy for the overall EA block in the EA4 GPM is similar to Eq. (3). However, additional spillovers from country level shocks to inflation and BLT are assumed to affect EA inflation and its expectations. Monetary policy therefore reacts to inflation and output dynamics at the EA level-the ECB targets euro area inflation and output gap- but it also allows heterogeneous credit conditions in individual economies. In addition, other common shocks like world demand and commodity prices, and also area wide liquidity shocks and capital requirement changes, generate area-wide shocks.

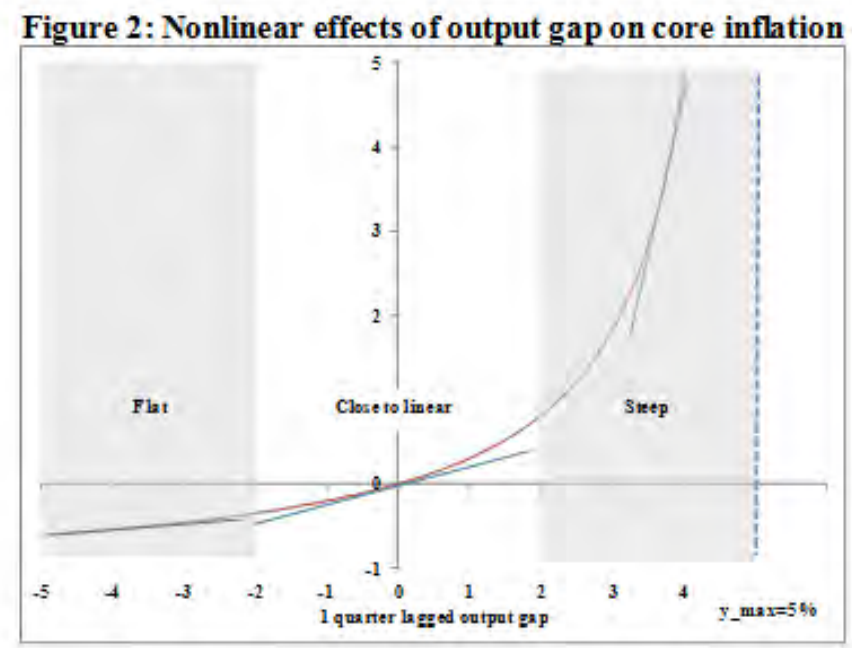

$\lambda_{2 x}$ in equations (2) and in (A2) represent the effect of lagged output gap on $\pi_{i, t}^{x}-\lambda_{i, 1 x} \pi_{i, t+4}^{x}-$ $\left(1-\lambda_{i, 1 x}\right) \pi_{i, t-1}^{x}-f(R E E R$, past headline and core inflation differential) .

The EA4 GPM also features important nonlinearities such as the zero lower bound (ZLB) on nominal interest rates, as well as the convex shape of the Phillips Curve discussed in several other studies (e.g. IMF 2012). ${ }^{9}$ The idea is to better capture the current debate on output gaps and the inflation/deflation spiral in the EA. The nonlinear Phillips curve is steep or close to vertical when the output gap is largely positive. However, it flattens out when in the case of a significant slack in the economy. In turn, this form of Phillips curve avoids protracted deflationary spirals but it also enables having strong inflationary pressures when the economy is above its productive capacities. The functional form is very similar to the one used in Laxton et al (1995), Debelle et al (1997) and Laxton et al (1999). Without loss

\footnotetext{
${ }^{8}$ See Appendix IV for the country-specific aggregate demand and inflation equations. In addition, gasoline and consumer food prices are modeled in the same way as in GPM6.

${ }^{9}$ The model also contains an option to non-linearize $\lambda_{1}$ and $\lambda_{3}$. The latter might be useful in some simulations to enhance the flexibility of prices or price (real exchange rate) convergence within the union (for example in order to avoid large cyclicality in price dynamics).
} 
of generality, the rest of the EA is modeled as a residual, in that its dynamics is calculated after the model is solved for the EA block and the four large economies.

\section{Model Properties, Parameterization and Simulation results}

\section{A. Parameterization and Model Fit}

The calibration /estimation methodology for the parameters of the EA4 GPM is performed to ensure that the model properties are sensible and broadly consistent with priors for the EA economy and with historical data, thereby facilitating the interpretation of forecasts and policy implications. This approach of calibration and Bayesian estimation falls between fully micro-founded estimated DSGE models and pure time series models. Similar to GPM6, a large proportion of the parameters are calibrated to account for county level heterogeneity (Table 1).

As some of our important quarterly data series (in particular the Bank Lending Survey data) used in the model start from the year 2003, the degrees of freedom in our estimation are seriously limited. Only six parameters per large EA country were estimated (24 in total while parameters of the rest of world are taken from GPM6) using Bayesian methods. These are the elasticities with respect to real interest rates and real exchange rates in the aggregate demand equation $\left(\beta_{3}\right.$ and $\left.\beta_{4}\right)$, the coefficients on the output gap $\left(\lambda_{2 x}\right)$ and on the real exchange rate $\left(\lambda_{3 x}\right)$ in the Phillips-curve equation, and the short-term adjustment terms in the gas and food price equations. The priors were chosen as the corresponding EA parameters in GPM6. The estimation results (Table 1), reveal important differences between country-level and EA-wide parameters. Parameters were generally not significantly different from the priors; data were not too informative for identifying these parameters. Germany's and France's output were estimated to be the most, while Italy and Spain to be the least sensitive to real interest rate movements $\left(\beta_{3}\right)$. This might show that in the latter two countries credit conditions were more affected by non-price related terms than in the former two economies. Interestingly, the Phillips curves for core inflation in all countries but France are estimated to be steeper $\left(\lambda_{2 x}\right)$ than in the eurozone as a whole. This can be the result of the fact that the rest of the countries in the eurozone are more open economies, and in turn would have flatter Phillips curves. Unfortunately, the short sample size did not allow us to test for possible structural changes in the parameters at the global financial crisis.

A useful feature of the EA4 GPM is that it allows for intra-EA spillovers. The channels of spillovers linking EA economies to the rest of EA and the world are specified through spillover coefficients, which are calculated from the elasticities of trade and commodity prices with respect to output in GPM6 ${ }^{10}$ (Table 2). Interestingly, for a given shock, the biggest spillover to Germany comes from the rest of the world (RC6, including UK and China) besides the rest of EA, implying strong economic linkages between Germany and non-EA economies. In contrast, France, Italy, and Spain are more exposed to shocks

\footnotetext{
${ }^{10}$ Appendix IV of Carabenciov and others (2013) provides detailed description on the calculation of the spillover coefficients.
} 
generated within the Eurozone, and they all pass on significant spillovers to the rest of EA (but less than Germany).

Table 1: Calibrated and estimated country-level parameters

\begin{tabular}{|c|c|c|c|c|c|c|c|c|}
\hline \multirow{2}{*}{\multicolumn{9}{|c|}{ Estimated parameters: }} \\
\hline & & & & & & & & \\
\hline & Distr & $\begin{array}{l}\text { Prior } \\
\text { mean }\end{array}$ & se & \multicolumn{4}{|c|}{ Posterior mode } & calibrated \\
\hline beta3 & gamma & 0.10 & 0.20 & 0.13 & 0.10 & 0.07 & 0.06 & 0.10 \\
\hline beta 4 & gamma & 0.07 & 0.20 & 0.08 & 0.11 & 0.05 & 0.09 & 0.07 \\
\hline lambda2x & gamma & 0.24 & 0.20 & 0.35 & 0.23 & 0.40 & 0.38 & 0.24 \\
\hline lambda3x & gamma & 0.15 & 0.20 & 0.12 & 0.12 & 0.13 & 0.10 & 0.15 \\
\hline iota_gas1 & beta & 0.14 & 0.10 & 0.27 & 0.17 & 0.32 & 0.24 & 0.14 \\
\hline iota_cfood1 & beta & 0.31 & 1.00 & 0.23 & 0.38 & 0.49 & 0.28 & 0.31 \\
\hline \multicolumn{9}{|c|}{ Calibrated parameters: } \\
\hline alpha1 & $\ldots$ & $\ldots$ & $\ldots$ & 0.72 & 0.72 & 0.72 & 0.72 & 0.72 \\
\hline alpha2 & $\ldots$ & $\ldots$ & $\ldots$ & 0.10 & 0.10 & 0.10 & 0.10 & 0.10 \\
\hline alpha3* & $\ldots$ & $\ldots$ & $\ldots$ & 0.10 & 0.10 & 0.10 & 0.10 & 0.10 \\
\hline alpha4* & $\ldots$ & $\ldots$ & $\ldots$ & 0.20 & 0.20 & 0.20 & 0.20 & 0.20 \\
\hline beta1 & $\ldots$ & $\ldots$ & $\ldots$ & 0.76 & 0.76 & 0.76 & 0.76 & 0.76 \\
\hline beta2 & $\ldots$ & $\ldots$ & $\ldots$ & 0.04 & 0.04 & 0.04 & 0.04 & 0.04 \\
\hline beta5 & $\ldots$ & $\ldots$ & $\ldots$ & -0.01 & -0.01 & -0.01 & -0.01 & -0.01 \\
\hline beta6 & $\ldots$ & $\ldots$ & $\ldots$ & 0.00 & 0.00 & 0.00 & 0.00 & 0.00 \\
\hline beta_fact & $\ldots$ & $\ldots$ & $\ldots$ & 0.55 & 0.55 & 0.55 & 0.55 & 0.55 \\
\hline beta_fact_res & $\ldots$ & $\ldots$ & $\ldots$ & 2.00 & 2.00 & 2.00 & 2.00 & 2.00 \\
\hline chi & $\ldots$ & $\ldots$ & $\ldots$ & $\ldots$ & $\ldots$ & $\ldots$ & $\ldots$ & 1.00 \\
\hline delta & $\ldots$ & $\ldots$ & $\ldots$ & $\ldots$ & $\ldots$ & $\ldots$ & $\ldots$ & 0.10 \\
\hline dot_lz_bar_ss_EU & $\ldots$ & $\ldots$ & $\ldots$ & $\ldots$ & $\ldots$ & $\ldots$ & $\ldots$ & 0.00 \\
\hline gammal & $\ldots$ & $\ldots$ & $\ldots$ & $\ldots$ & $\ldots$ & $\ldots$ & $\ldots$ & 0.69 \\
\hline gamma2 & $\ldots$ & $\ldots$ & $\ldots$ & $\ldots$ & $\ldots$ & $\ldots$ & $\ldots$ & 1.31 \\
\hline gamma4 & $\ldots$ & $\ldots$ & $\ldots$ & $\ldots$ & $\ldots$ & $\ldots$ & $\ldots$ & 0.20 \\
\hline iota_cfood2 & $\ldots$ & $\ldots$ & $\ldots$ & 0.03 & 0.03 & 0.03 & 0.03 & 0.03 \\
\hline iota_food3 & $\ldots$ & $\ldots$ & $\ldots$ & $\ldots$ & $\ldots$ & $\ldots$ & $\ldots$ & 0.10 \\
\hline iota_gas2 & $\ldots$ & $\ldots$ & $\ldots$ & 0.34 & 0.34 & 0.34 & 0.34 & 0.34 \\
\hline iota_oil3 & $\ldots$ & $\ldots$ & $\ldots$ & $\ldots$ & $\ldots$ & $\ldots$ & $\ldots$ & 0.10 \\
\hline kappa $1 *$ & $\ldots$ & $\ldots$ & $\ldots$ & 20.08 & 20.08 & 20.08 & 20.08 & 20.08 \\
\hline kappa2* & $\ldots$ & $\ldots$ & $\ldots$ & 0.00 & 0.00 & 0.00 & 0.00 & 0.00 \\
\hline lambda1x & $\ldots$ & $\ldots$ & $\ldots$ & 0.70 & 0.70 & 0.70 & 0.70 & 0.70 \\
\hline lambda4x & $\ldots$ & $\ldots$ & $\ldots$ & 0.05 & 0.05 & 0.05 & 0.05 & 0.05 \\
\hline phi & $\ldots$ & $\ldots$ & $\ldots$ & $\ldots$ & $\ldots$ & $\ldots$ & $\ldots$ & 0.83 \\
\hline tau & $\ldots$ & $\ldots$ & $\ldots$ & 0.20 & 0.20 & 0.20 & 0.20 & 0.20 \\
\hline theta & $\ldots$ & $\ldots$ & $\ldots$ & 0.30 & 0.30 & 0.30 & 0.30 & 0.30 \\
\hline
\end{tabular}

Source: IMF staff estimations

* The parameter was defined as a parameter for the Rest of the EA country group.

Source: IMF staff calculations 
Table 2: Spillover coefficients across countries and regions*

\begin{tabular}{|c|c|c|c|c|c|c|c|c|c|c|}
\hline $\begin{array}{l}\text { from: } \\
\text { to: }\end{array}$ & GR & FR & IT & $\mathrm{SP}$ & Rest of EA & US & $\mathrm{JA}$ & EA6 & LA6 & RC6 \\
\hline$\overline{\text { GR }}$ & $\ldots$ & 0.04 & 0.03 & 0.02 & 0.09 & 0.03 & 0.01 & 0.03 & 0.01 & 0.09 \\
\hline FR & 0.04 & $\ldots$ & 0.02 & 0.02 & 0.04 & 0.02 & 0.00 & 0.01 & 0.00 & 0.04 \\
\hline IT & 0.03 & 0.03 & $\ldots$ & 0.02 & 0.03 & 0.02 & 0.00 & 0.01 & 0.00 & 0.04 \\
\hline SP & 0.02 & 0.03 & 0.02 & $\ldots$ & 0.04 & 0.01 & 0.00 & 0.01 & 0.01 & 0.04 \\
\hline Rest of EA & 0.12 & 0.06 & 0.03 & 0.02 & $\ldots$ & 0.04 & 0.01 & 0.02 & 0.00 & 0.10 \\
\hline EA & 0.31 & 0.24 & 0.19 & 0.12 & 0.26 & 0.03 & 0.01 & 0.02 & 0.01 & 0.08 \\
\hline
\end{tabular}

* The direct impacts of foreign demand shocks are the spillover coefficients multiplied by $\beta_{\text {factres }}$ (calibrated at 2). For more details see Appendix V.

Source: IMF staff calculations.

\section{B. Simulation results}

When constructing a model for forecasting and policy analysis, one important consideration is the response of the model to various shocks. This section presents the dynamic responses to several types of shocks through impulse response functions and simulations, and describes the major mechanisms that are at work in the model. The shocks analyzed can be grouped into three types: (1) negative demand shocks emanating from either one (or all) major EA country, or from outside the EA; (2) shocks leading to a deviation of the interest rate from the monetary reaction function; (3) financial (BLT) shocks. ${ }^{11}$

Figure 3 shows that a negative one percentage point country specific demand shock emanating from Germany feeds into lower demand in other economies immediately. As a result, core inflation drops and the ECB lowers interest rates, accompanied by a gradual depreciation of the euro. In turn, the depreciation of the currency makes the response of headline inflation more muted (though in the scenario headline inflation declines more quickly due to decline of oil price in the first few quarters). ${ }^{12}$

\footnotetext{
${ }^{11}$ Only impulse responses around the non-stochastic steady state are presented in this section. Appendix II presents additional simulations starting from non-steady states with a case when policy rate is at the ZLB and the output gap is negative.

12 The reason is that the drop in crude oil prices due to lower global demand is partly offset by the depreciation of the euro, so that domestic gasoline and food prices do not fall as much as core inflation does.
} 
Figure 3: A negative demand shock in Germany RES_YY_GR $=-1$; 1-perlod shock
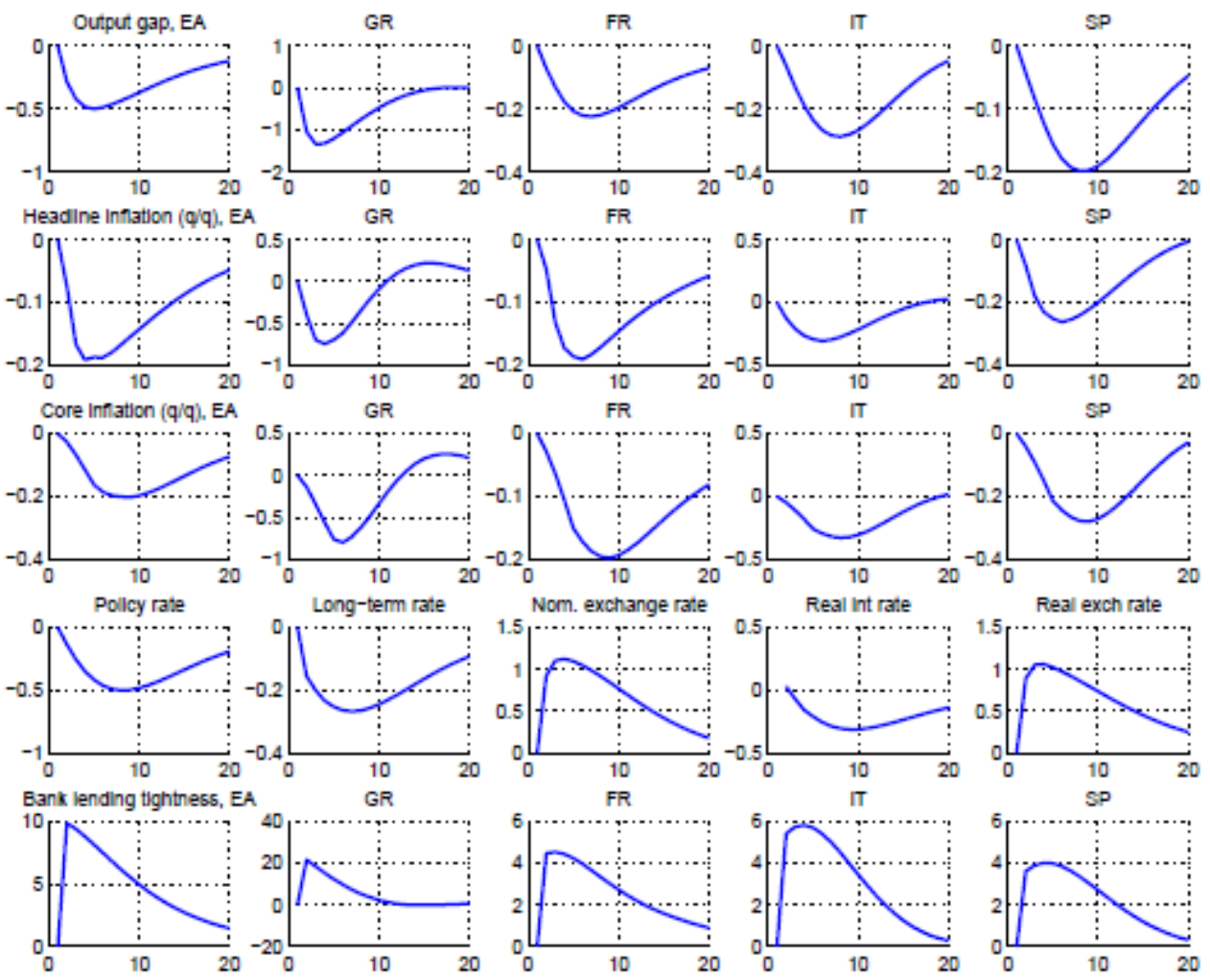

However, what happens in the source country of the shock, Germany, and in the other EA countries is markedly different, largely due to a fixed nominal exchange rate. In a currency union, the only way in which relative prices can adjust is through inflation (and ultimately through real unit labor cost), but not through bilateral exchange rates. Therefore, a negative demand shock in Germany would tend to depreciate the German real exchange rate, which implies that inflation in Germany needs to fall faster than in other countries. As the ECB only targets area-wide inflation and output, the cut in its policy rate would be less than warranted if the Bundesbank were to react independently. As a result, German real interest rates increase more than in other countries.

Figure 3 also shows that, as the shock starts to fade, the picture is reversed. German real interest rates converge back to their steady state faster than in other countries, which adds an additional boost to the German economy. As a result, both headline and core inflation in Germany increase beyond their original steady state before finally converging back to their steady state. Therefore, in the case of country specific demand shocks originating in member countries of a currency union, price volatility and cyclicality in the source country is amplified due to the absence of an exchange rate channel. 
Figure 4: A common negative demand shock in the euro area RESC_YY_EU $=-1$; 1 -perlod shock
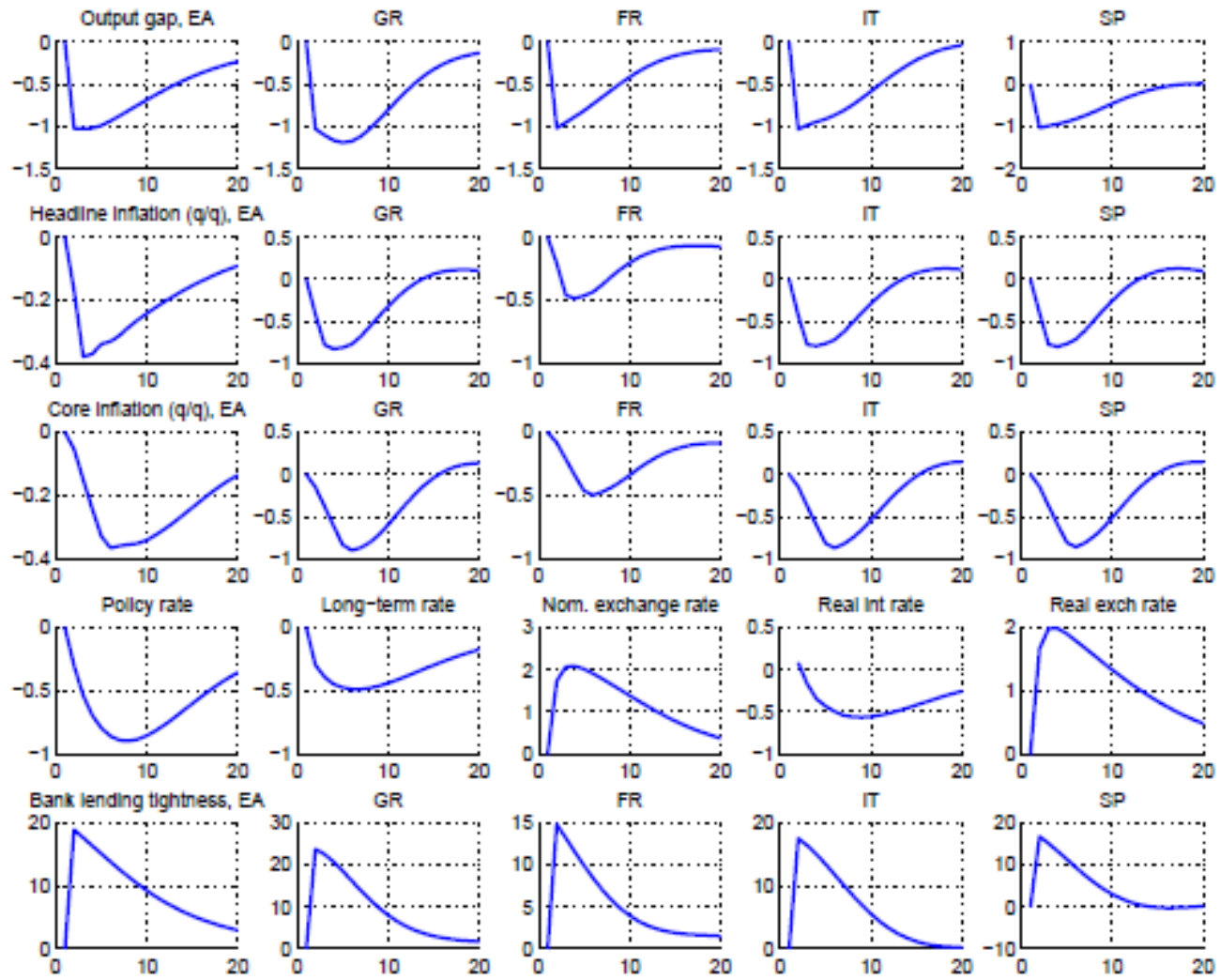

Figure 4 illustrates the role of the bilateral exchange rate when a common area-wide negative demand shock hits the EA. In this case all countries are affected by the same negative demand shock, and thus no significant bilateral real exchange rate adjustment is required across euro area countries. In this case the cyclicality in prices disappears, the monetary authority decreases area wide nominal interest rates, and real interest rates drop in all countries. Although some differences occur between countries in the extent of price reactions (and in turn in bilateral real exchange rates), these differences are smaller than with country specific demand shocks. The initial drop in inflation gradually fades away in all countries. 
Figure 5: A euro area-wide interest rate shock RES_RS_EU $=-1$; 1-perlod shock
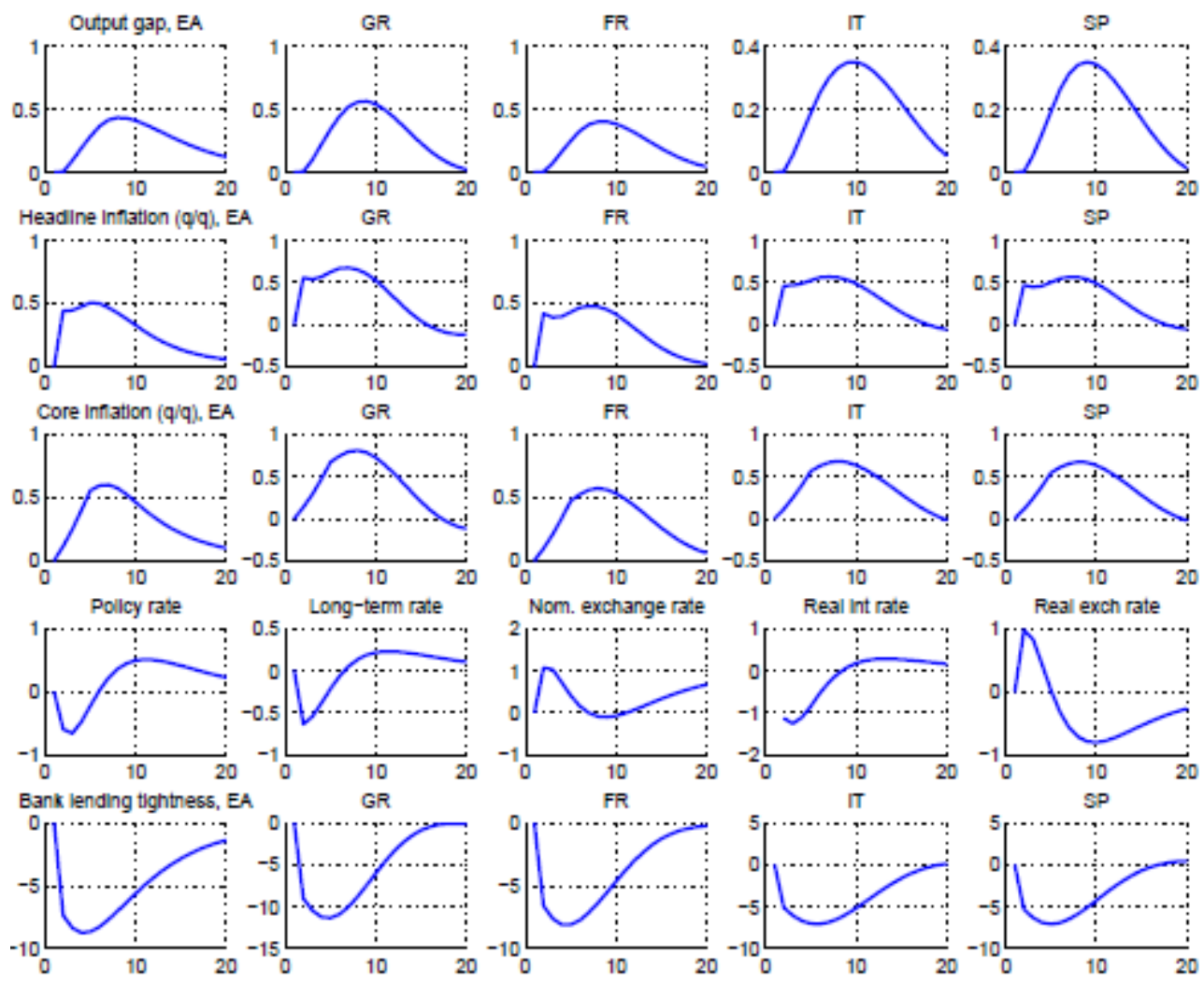

Figure 5 studies the effects of an exogenous departure from the interest rate reaction function, specifically a transitory drop in the EA interest rate. The responses are as expected, with the output gap rising in all countries as the real interest rate is temporarily reduced and the real exchange rate is temporarily more depreciated than in steady state.

There are, however, country level differences. The boost to output is most significant for Germany, but somewhat lower in Italy and Spain. There are two reasons: (1) Germany and France have the largest estimated sensitivity of output to real interest rate changes; (2) Despite Germany's low estimated sensitivity of output to real exchange movements, its output response is amplified by the spill-back from the rest of the world, given Germany's stronger connection with non-EA economies described in Section II.A. The same holds for the response of core inflation, with Germany's inflation most responsive to a monetary policy shock. 
Figure 6: A country-specific bank lending tightening shock in Germany

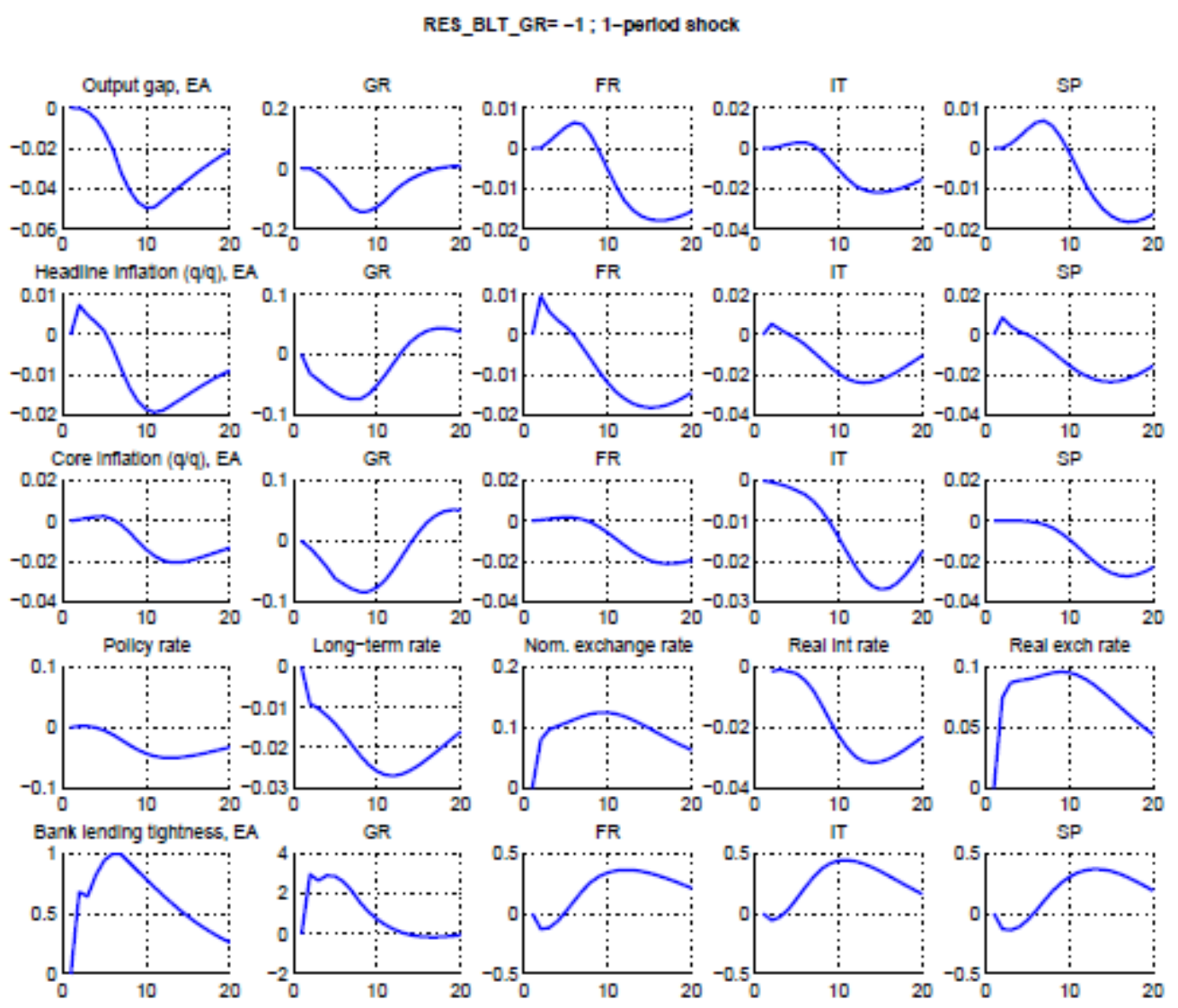

To shed light on some policy simulations below, Figure 6 and Figure 7 show the impacts of shocks to Bank Lending Tightening (BLT), an illustrative increase in BLT in Germany (Figure 6) and a more realistic, common bank lending shock (Figure 7). These shocks have a long-lasting and slowly evolving effect on output and prices. Financial tightening shocks lead to a drop in output and lower inflation. The monetary reaction is a gradual decrease in interest rates. In the case of country-specific (in this case a German) shock the magnitude of the impact effect on output in the EA countries outside of Germany is not very significant and they are also not very different, partly because of a lack of sufficient differentiation in the calibrated parameters. As in the case of a country specific demand shock, there is also a cyclicality which can be mostly explained by the fact that bilateral real exchange rate adjustments can only be achieved through price adjustments. In the more realistic case, however, when there is a common bank lending tightening, the impacts on output in all countries are far larger and more synchronized and the cyclicality is less prominent.

In addition, Appendix II shows that when monetary policy is at the zero lower bound, the negative output effects are larger than when the simulations start at the non-stochastic steady state. Finally, as with demand shocks, there is cyclicality in inflation that arises due to the presence of a currency union. 
Figure 7: A common bank lending tightening shock

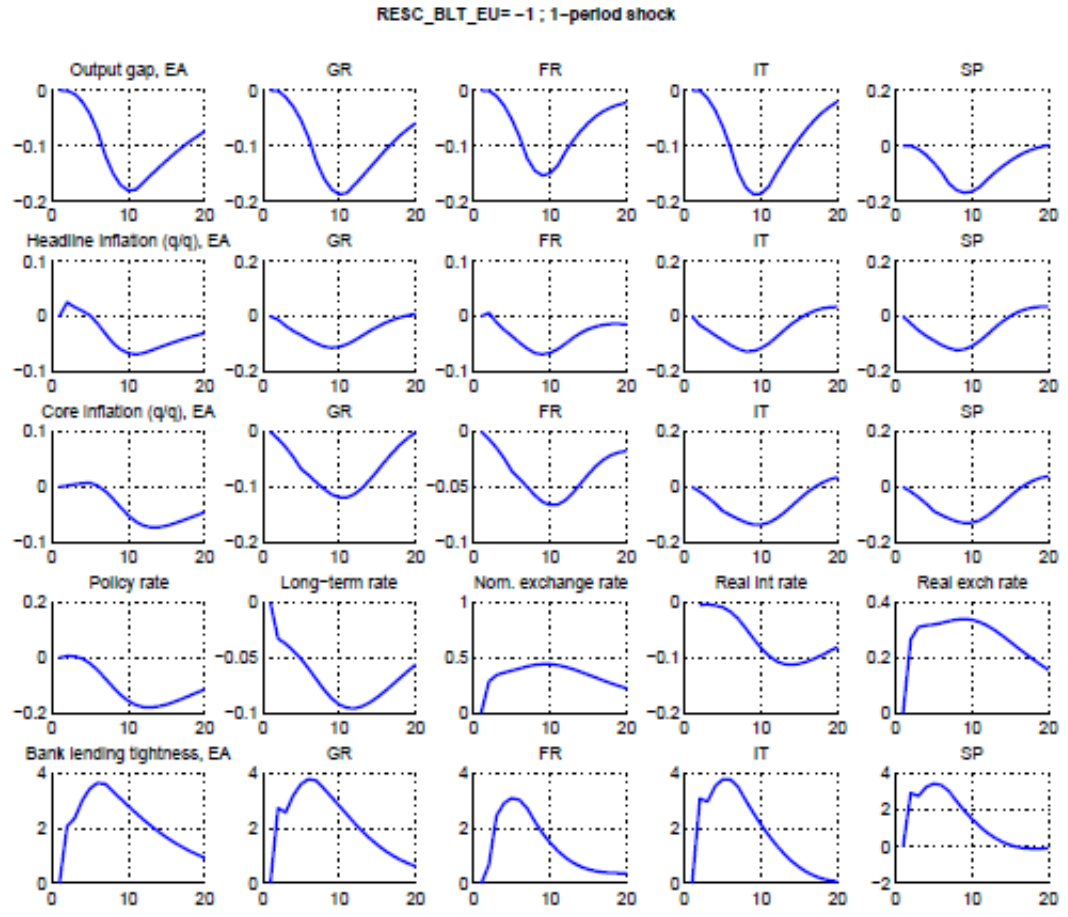

Figure 8: Counterfactual exercise of looser bank lending standards after 2007Q4

(Percentage difference between actual and counterfactual data) Common Bank lending shock, shock starting from $2007 \mathrm{Q}$
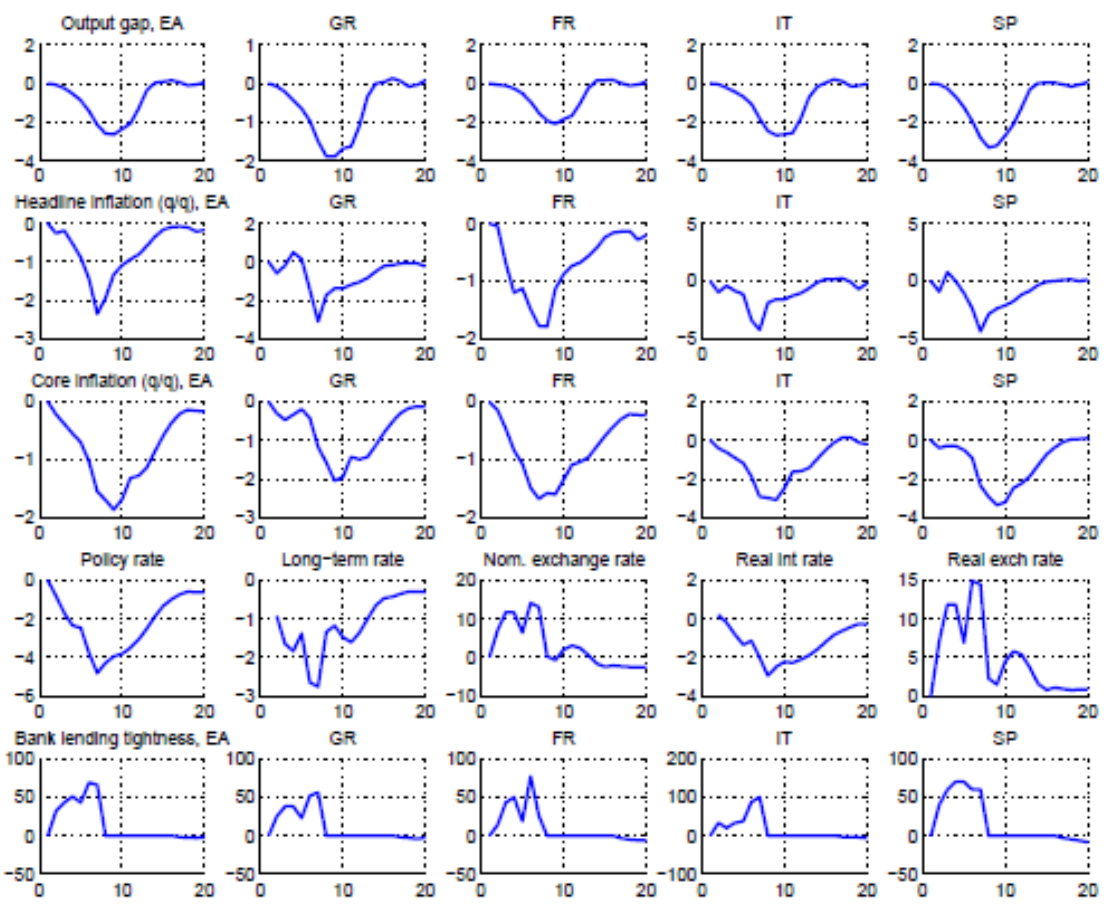

Figure 8 demonstrates the importance of how synchronized and significant BLT shocks were by using a counterfactual analysis. This simulation captures what would have happened if all 
other estimated shocks had happened but not the BLT shocks such that the BLT level have stayed constant at the level observed before the Great Financial Crisis. This simulation highlights that a significant part (around 2 percent) of the euro area's output drop during the first wave of the Financial Crisis (2008-2009) can be attributed to tightening in credit conditions. This negative 'financial' shock was more or less evenly distributed across countries with the exception of Spain, which suffered disproportionately from the financial shock. Inflation would have also been higher for a prolonged period of four about years.

Finally, Figure 9 shows that, on the other hand, the second financial shock in late 2011 and early 2012 had a more diverse and more muted impact on the euro area as a whole and on individual countries, in particular ${ }^{13}$ German and Spanish output were hardly affected by the shock, while the output of France and Italy would have been reacting more strongly. Inflation would also have been significantly higher (by about 0.5 percent) for two to three years after the shock.

Figure 9: Counterfactual exercise of looser bank lending standards after 2011Q3

(Percentage difference between actual and counterfactual data) Common Bank lending shock, shock starting from $2011 \mathrm{Q} 4$
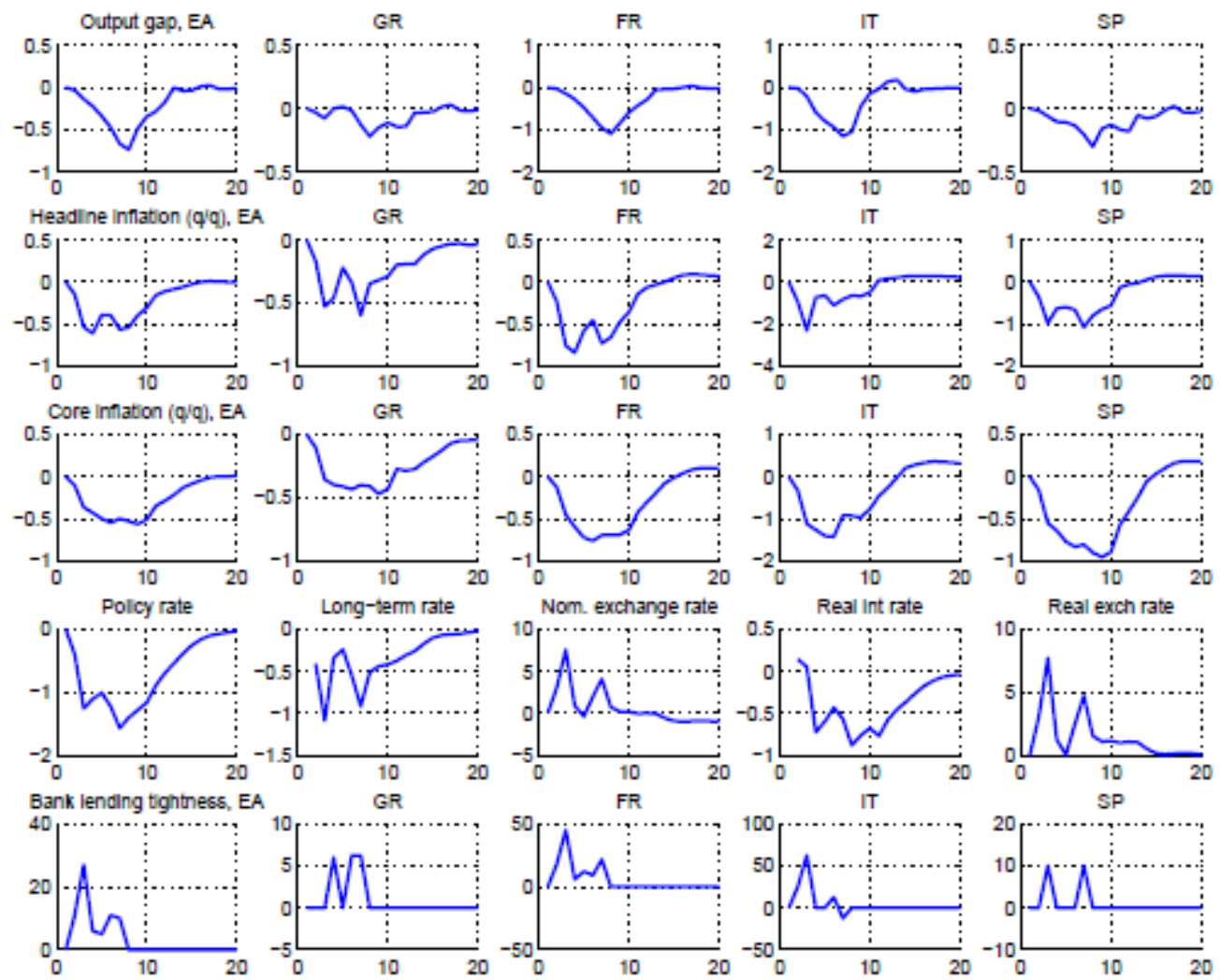

\footnotetext{
${ }^{13}$ The second counterfactual simulation shows what would have happened if BLT shocks were such that BLT remained flat after 2011Q3. In the case of Spain, the muted response of output in the second financial shock comes from a much negative loss in output during the first shock.
} 


\section{FORECAST PERFORMANCE}

One can measure the pure out-of-sample forecast performance properties of the model by the Root Mean Squared Errors (RMSE). We compare the RMSE of EA4 GPM with GPM6 on the EA block, and find that the model fit is similar. As there is no benchmark RMSE for the four EA countries in GPM6, we present the RMSE over several in-sample forecast horizons (one, four, and eight quarters) for the key variables (real GDP growth and inflation) in Appendix Table A1. Overall, the forecast performance for real GDP growth at the EA level is close to the one of GPM6, with some marginal improvement over the longer horizon. At the country level, the model finds it more challenging to forecast Spain and Italy's growth in the short run, while at longer horizons the forecast performance improves markedly. On inflation, the EA4 GPM underperforms GPM6 in the short run, but the difference is diminishing over time. In sum, the more disaggregated model does not have worse longerterm forecast performance than the more aggregated model at the eurozone level, while it enables us to make forecasts at country level. Still, in a practical forecast exercise the model's performance can be significantly improved by adding additional information.

Next we turn our attention on how to incorporate additional information to the forecasts. To do so, we show an illustrative forecasting exercise based on the EA4 GPM that was carried out in 2014 Q2. The July 2012 WEO projection was partially based on this model run, but obviously this run only served as one input among many others to the final projection.

For forecasting purposes global economic conditions are imported from GPM6 and treated as exogenous. As a starting point of the forecast, "nowcasting" methods are used. These forecasts make use of high frequency indictors such as country level industrial production and PMIs. This improves the quality of the forecast, by linking it directly to the latest economic indicators, and by making it consistent with countrylevel developments.

Developments in EA up to 2014 Q1 were mixed. Q1 growth in Germany and Spain overshot the April 2014 WEO forecast, while France, Italy and several other EA economies including the Netherlands underperformed. Inflation dipped to new lows well below expectations, reflecting in part continued slack in aggregate demand across the region. Bank lending and credit growth in the EA remained weak, owing to

Table 3A. Selected Euro Area Countries: Growth Forecasts, 2014-16

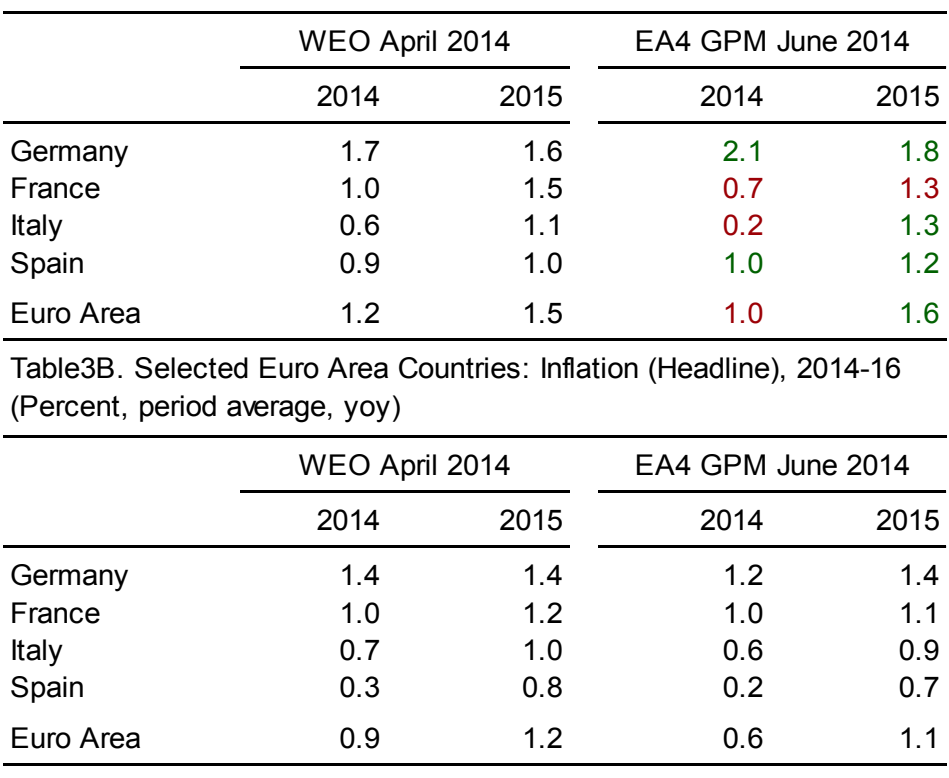

Sources: World Economic Outlook database; and staff simulations. 
continued deleveraging pressures and fragmentation.

During the same period, there was also some divergence in leading and high frequency indicators across countries: PMIs in several EA economies softened slightly, orders in Germany disappointed, but at the same time economic sentiments in EA remained relatively optimistic. Given continued downward pressure in inflation, the ECB was expected to take a policy action at its Governing Council meeting in early June, so that a policy rate cut of 10 to 15 basis points was assumed in the forecast. In addition, the fiscal stance of the four large EA economies and of the EA overall was assumed to remain broadly unchanged from the previous forecasting round.

Tables 3A and 3B and Appendix Figure 8 show the updated EA4 GPM forecast. Taking into account all euro area developments, together with updated global economic conditions imported from GPM6, the forecast suggests a slightly weaker EA outlook in 2014 compared to the IMF's April 2014 WEO. 2014 growth rates were revised down markedly in France (from 1.0 to 0.7 percent) and Italy (from 0.6 to 0.2 percent), while being offset somewhat by higher growth in Germany and Spain. As a result, the euro area was projected to grow at 1.0 percent in 2014, slightly below the April 2014 WEO forecast of 1.2 percent. Inflation was expected to edge down further, to 0.6 percent in 2014 compared to 0.9 percent in the April 2014 WEO forecast, before picking up modestly in the following year.

\section{Conclusions}

The GPM project is designed to improve the toolkit for studying both own-country and crosscountry linkages. In this paper introduces a special version of GPM that includes the four largest EA countries. The four economies Germany, France, Italy and Spain account for a very significant share of euro area output. Breaking the single EA block of GPM6 into five blocks, namely these four economies and the remaining economies of the EA, is therefore an important enhancement to the existing framework that captures intra-EA dynamics in much richer detail, including intra-EA spillovers, and also including the critical role of the single currency and therefore of a common monetary policy.

As illustrated in the previous sections, the EA countries are more vulnerable to domestic and external demand shocks because adjustments in the real exchange rate between EA countries occur more gradually through inflation differentials. Spillovers from tight credit conditions in each EA country are limited by direct trade channels and small confidence spillovers, but we also consider scenarios where banks in all EU countries tighten credit conditions simultaneously. In addition, the inclusion of more country-level information makes the forecasting framework more robust, and consistent with individual country-level forecasts carried out at the IMF. The approach taken accommodates differences between countries through different parameterizations of a small number of equations, including spillover coefficients. 
Our preferred parameterization of the model replicates many of the key features of the EA block in GPM6. For example, impulse response functions show the fundamentally different behavior of country-level inflation when bilateral nominal exchange rates cannot adjust in the face of idiosyncratic shocks, due to the presence of a currency union. The resulting cyclical price effects are likely to be amplified in the case of country-specific shocks, owing to the assumed reaction function of the European Central Bank, which is based on the aggregate EA-level price level and EA-level output. Monetary policy in EA4 GPM uses conventional inflation-forecast-based monetary reaction functions, as in other blocks of the model, while non-conventional monetary policies, for example targeted LTROs, can be represented as EAwide or country-level shocks to bank lending conditions.

Future research in this area will focus on constructing a version of EA4 GPM that incorporates other ongoing research work on GPM6, including a better integration of high frequency indicators in the forecast, as well as a further decomposition of the current emerging Asia and RC6 blocks by splitting out China and other large G20 economies. Given the increasing economic linkages between the EA and emerging market economies, this development will allow for a more comprehensive analysis of interactions among these economies (see Blagrave and others, 2013). 


\section{References}

Amano, R., D. Coletti, and T. Macklem, 1998, "Monetary Rules When Economic Behavior Changes", in: Monetary Policy Under Uncertainty: Papers from a Reserve Bank of New Zealand Workshop, June 29-30, 1998.

Bailliu, J. and P. Blagrave, 2010, "The Transmission of Shocks to the Chinese Economy in a Global Context: A Model-Based Approach”, Bank of Canada Working Paper, No. 2010-17.

Blagrave, P., P. Elliott, R. Garcia-Saltos, D. Hostland, D. Laxton and F. Zhang, 2013, "Adding China to the Global Projection Model", IMF Working Papers, WP/13/256.

Carabenciov, I., C. Freedman, R. Garcia-Saltos, O. Kamenik, D. Laxton, and P. Manchev, 2013, "GPM6-The Global Projection Model with 6 Regions", IMF Working Papers, $\mathrm{WP} / 13 / 87$.

Debelle, G. and D. Laxton, 1997, "Is the Phillips Curve Really a Curve? Some Evidence for Canada, The United Kingdom and the United States," IMF Staff Papers, Vol. 44, No. 2, June, pp. 249-82.

IMF, 2012, "World Economic Outlook: Coping with High Debt and Sluggish Growth", International Monetary Fund, Washington D.C.

IMF, 2014, "World Economic Outlook Update: An Uneven Global Recovery Continues", International Monetary Fund, Washington D.C.

Laxton, D., D. Rose and R. Tetlow, 1993, "Monetary Policy, Uncertainty and the Presumption of Linearity", Bank of Canada Technical Report, No. 63.

Laxton, D., G. Meredith and D. Rose, 1995, "Asymmetric Effects of Economic Activity on Inflation: Evidence and Policy Implications," IMF Staff Papers, Vol. 42, June, (Washington: International Monetary Fund).

Laxton, D., D. Rose and D. Tambakis, 1999," The U.S. Phillips Curve The Case for Asymmetry," Journal of Economic Dynamics and Control, Vol. 23, No. 9, pp. 145985.

Matheson, T., 2011, "New Indicators for Tracking Growth in Real Time", IMF Working Papers, WP 11/43.

Stock, J. and M. Watson, 1991, "A Probability Model of the Coincident Economic Indicators", in: Leading Economic Indicators: New Approaches and Forecasting Records, edited by K. Lahiri and G. Moore, Cambridge University Press. 


\section{Appendix I. Out-of-sample forecast performance (RMSEs)}

Table A1. Root Mean Squared Errors

\begin{tabular}{lccc}
\hline & 1Q ahead & 2Q ahead & 8Q ahead \\
\hline & Real GDP growth (q/q saar) \\
\hline EA (GPM6) & 2.8 & 2.7 & 2.9 \\
EA (EA4 GPM) & 2.8 & 2.7 & 2.7 \\
Germany & 3.6 & 3.5 & 3.7 \\
France & 3.0 & 2.7 & 2.2 \\
Italy & 3.9 & 3.5 & 3.1 \\
Spain & 4.7 & 3.6 & 2.7 \\
\hline \multicolumn{4}{c}{ Headline inflatin (q/q saar) } \\
\hline EA (GPM6) & 1.3 & 1.1 & 1.2 \\
EA (EA4 GPM) & 1.7 & 1.6 & 1.4 \\
Germany & 1.4 & 1.4 & 1.5 \\
France & 1.7 & 1.7 & 1.5 \\
Italy & 2.0 & 2.1 & 2.0 \\
Spain & 2.3 & 2.8 & 3.1 \\
\hline
\end{tabular}

Source: IMF stafff calculations. 


\section{Appendix II: Additional simulation results}

(Simulations starting at the zero lower bound of interest rates starting from 2014Q1)

Figure A1: A one percentage point negative demand shock in Germany RES_YY_GR = -1; 1-perlod shock starting from $2014 Q 1$
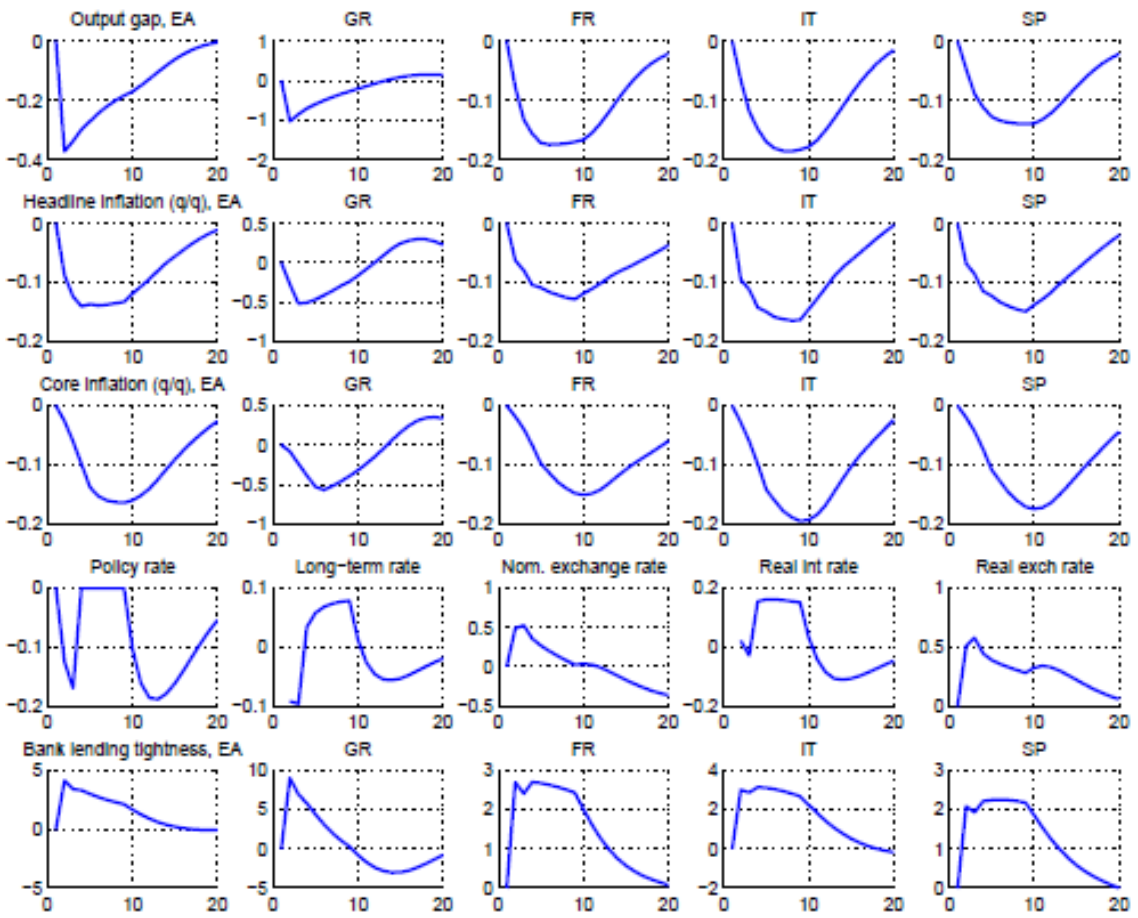

Figure A2: A one percentage point negative demand shock in France RES_YY_FR= -1 : 1-perlod shock starting from 2014 Q1
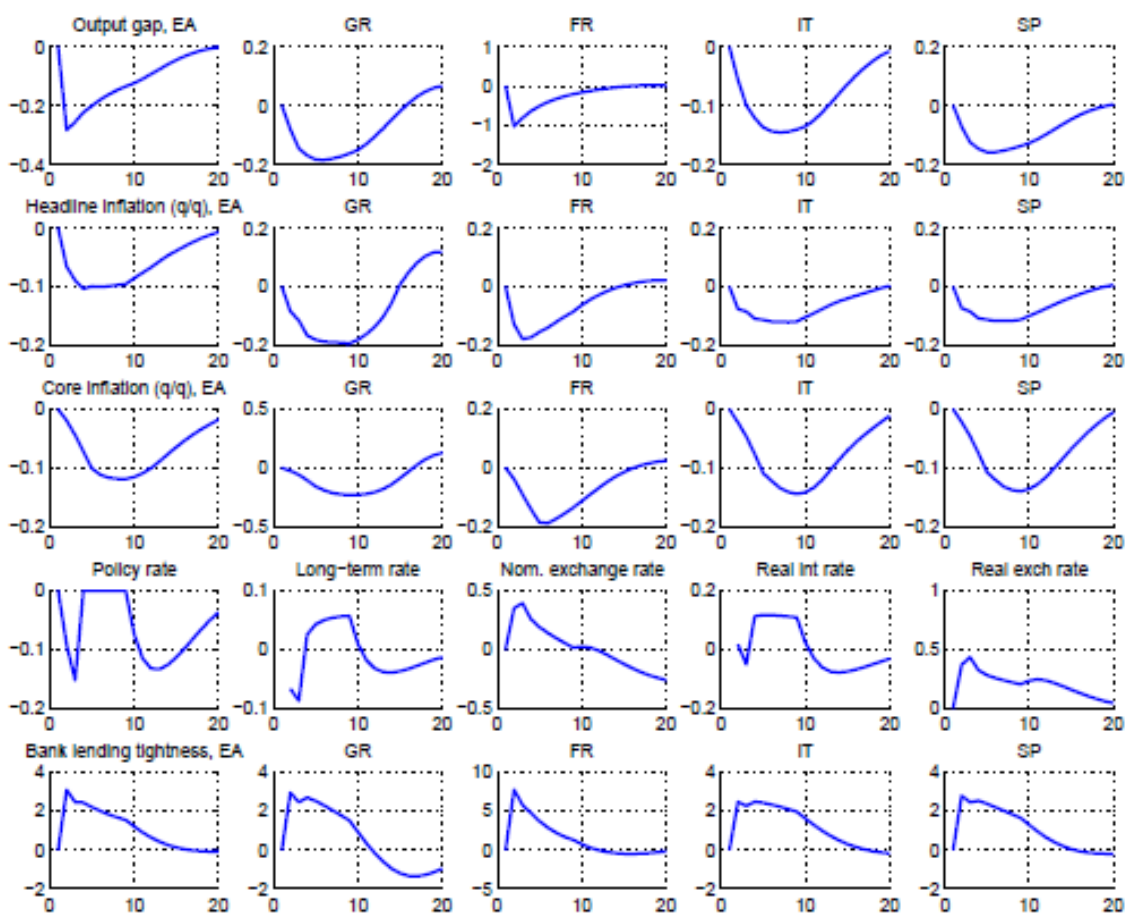
Figure A3: A one percentage point negative demand shock in Italy

RES_YY_IT=-1; 1-perlod shock starting from $2014 Q 1$
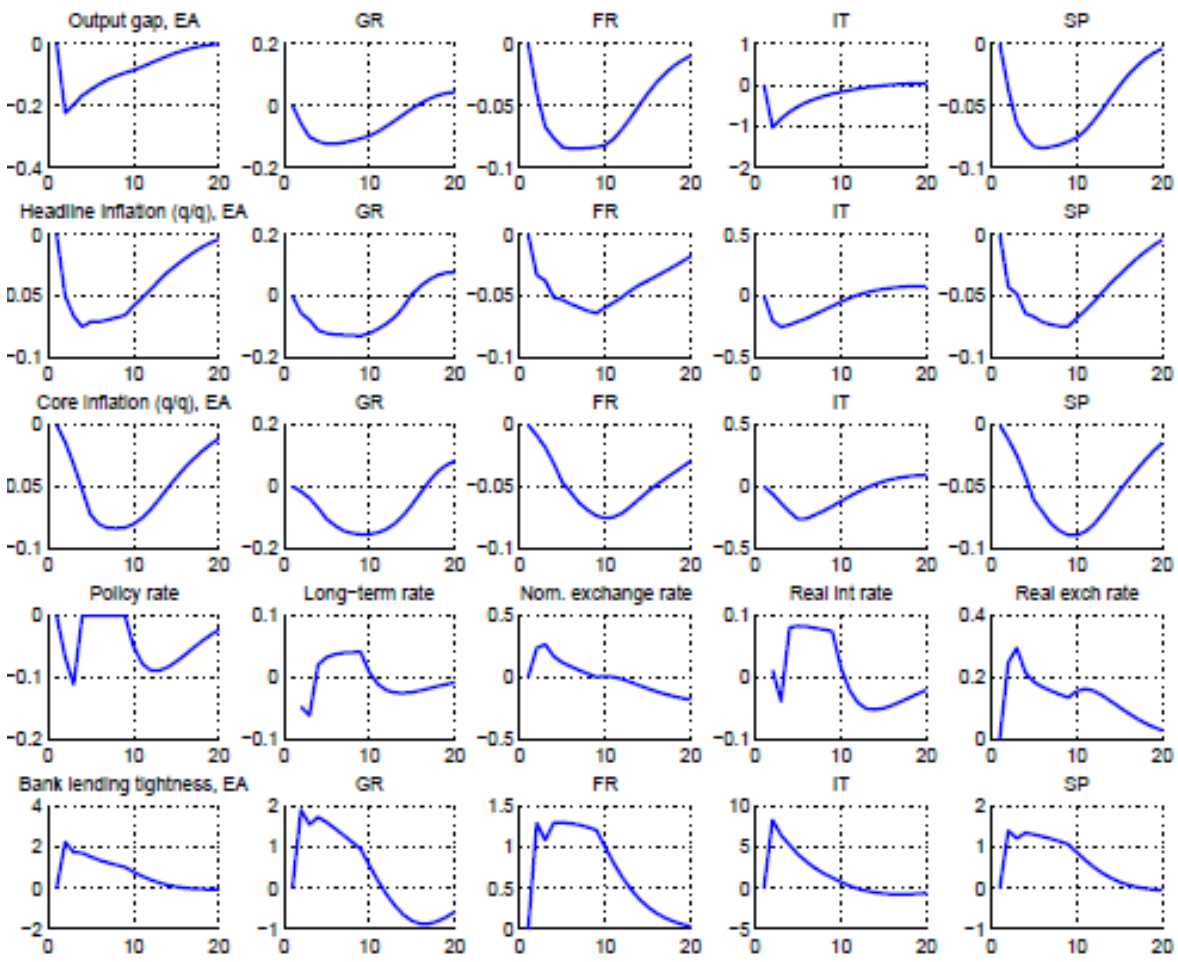

Figure A4: A one percentage point negative demand shock in Spain RES_YY_SP= -1 ; 1-perlod shock starting from 2014 Q1
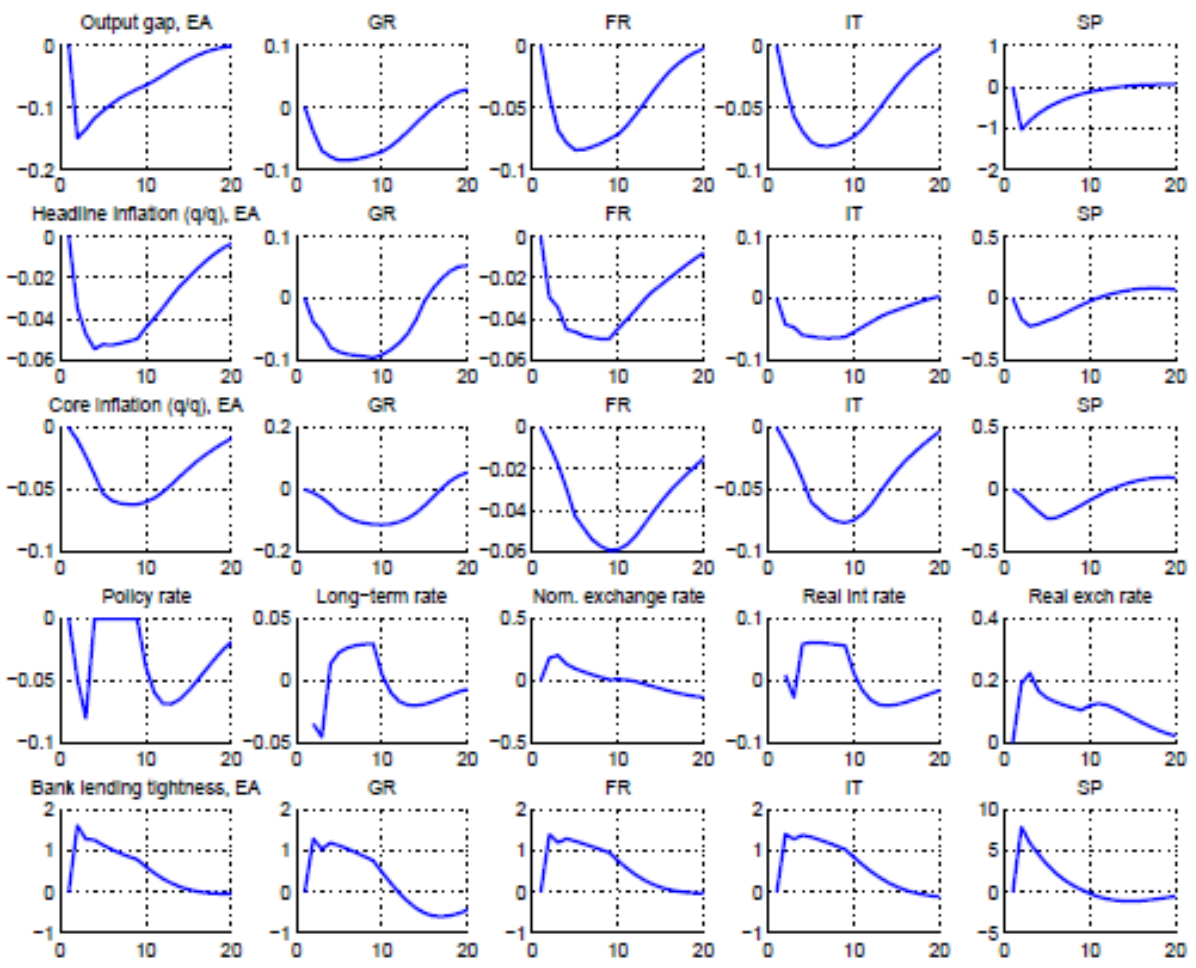
Figure A5: A one percentage point common negative demand shock in the euro area
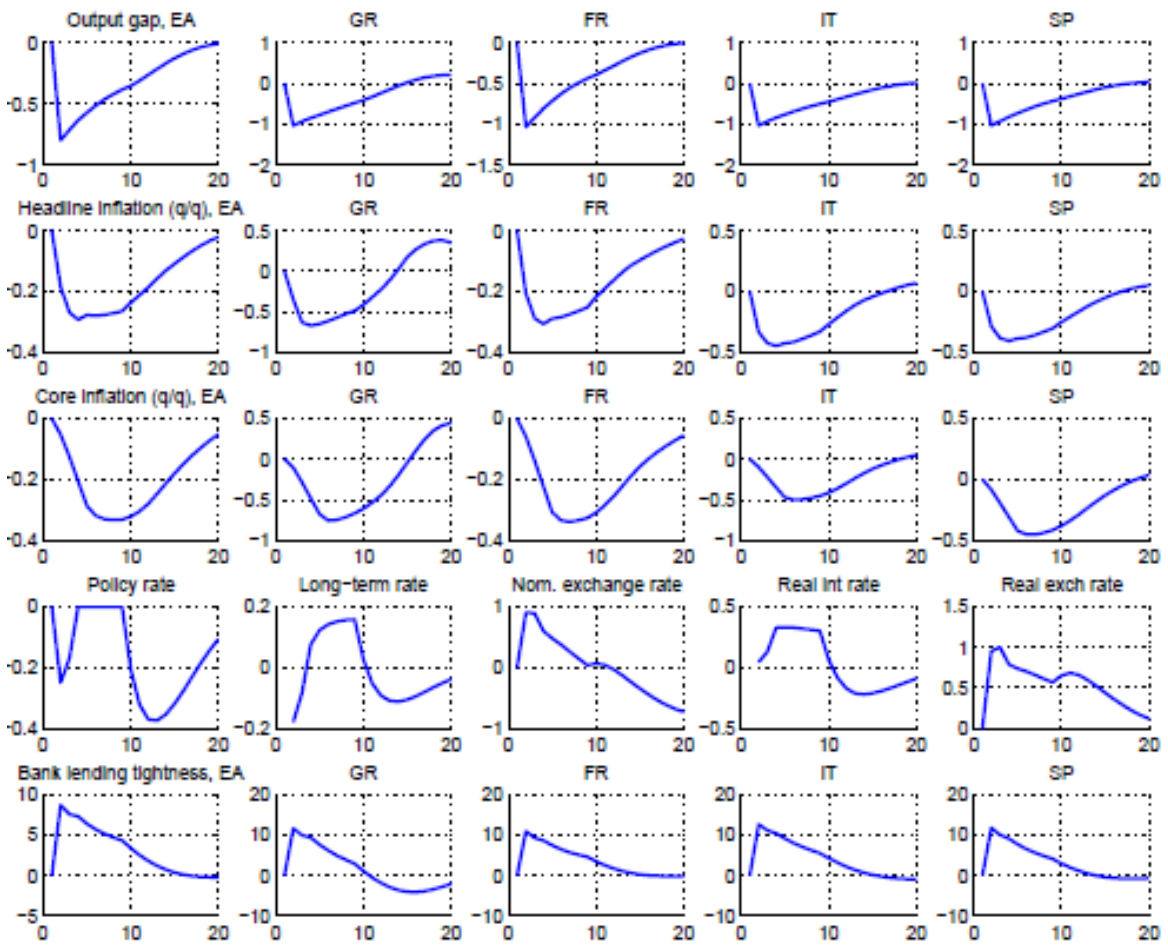

Figure A6: A country-specific bank lending tightening shock in Germany

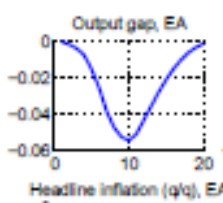

RES BLT_GR= $-1 ; 1$-period shock starting from 201401
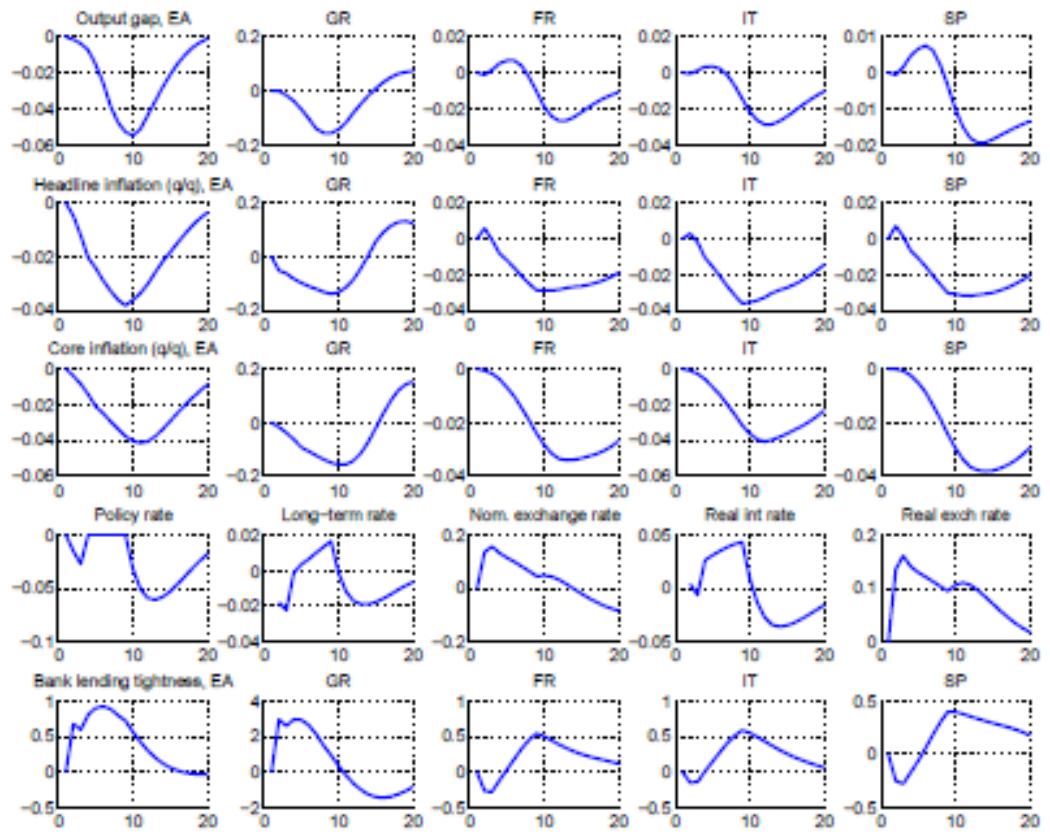
Figure A7: A common bank lending tightening shock

AESC BLT EU:-1, 1-pentod slock staring from 201401
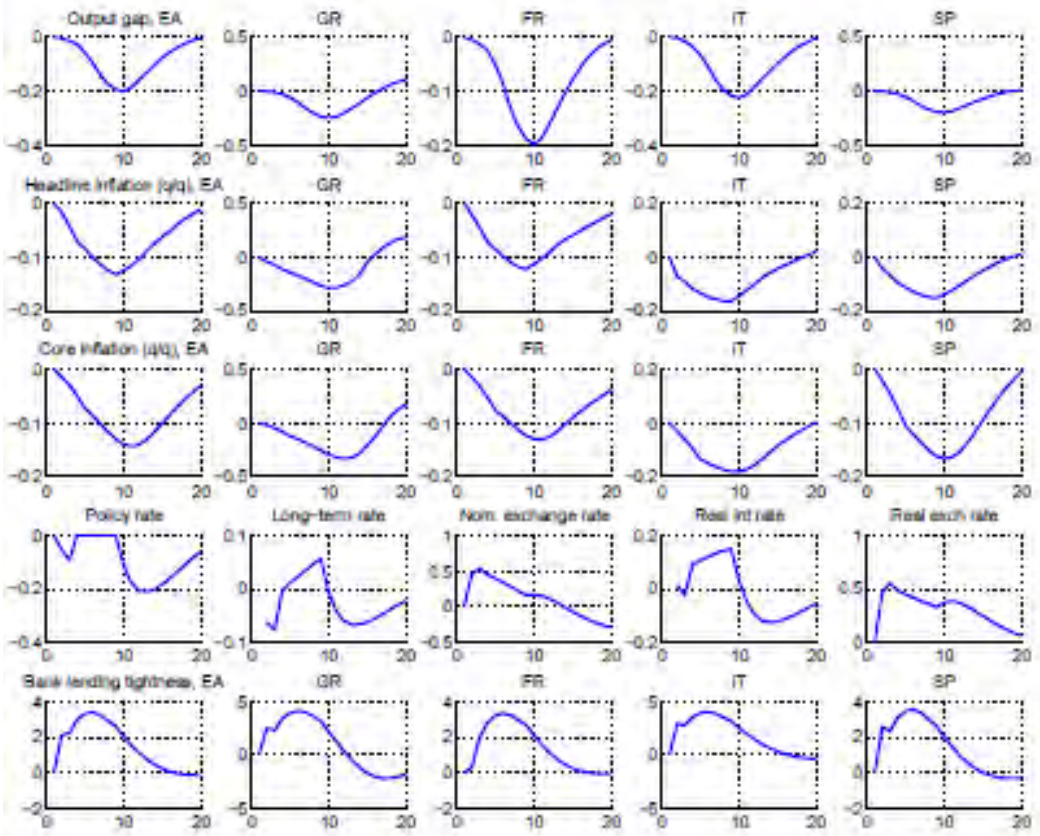

Figure A8: A one percentage point negative demand shock in the US

RES_YY_US= -1 ; 1-period shock starting from 2014 Q1
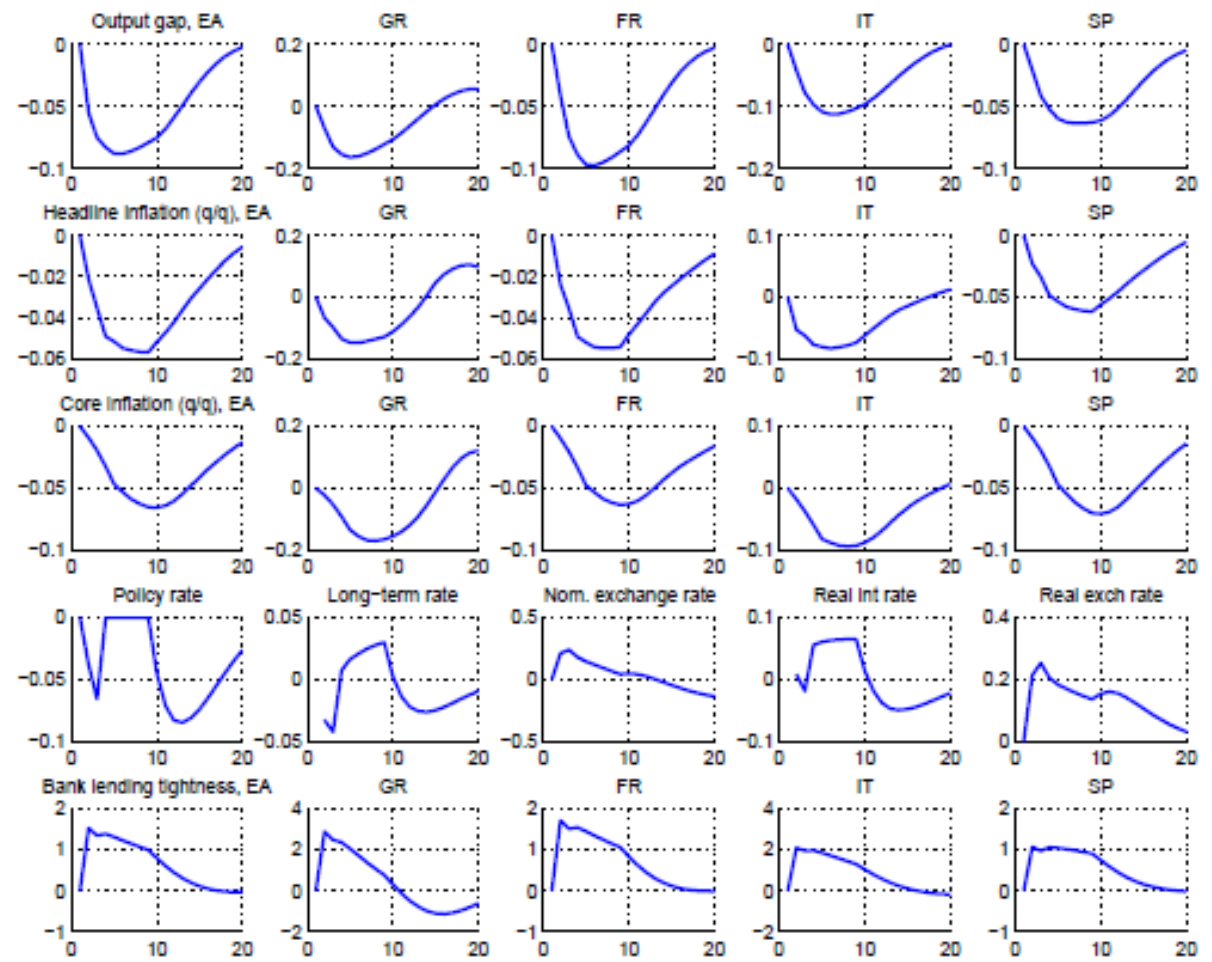
Figure A9: A 10 percent negative oil price shock

RES_LRPOIL_GAP_WORLD= -10 ; 1-perlod shock starting from $2014 Q 1$
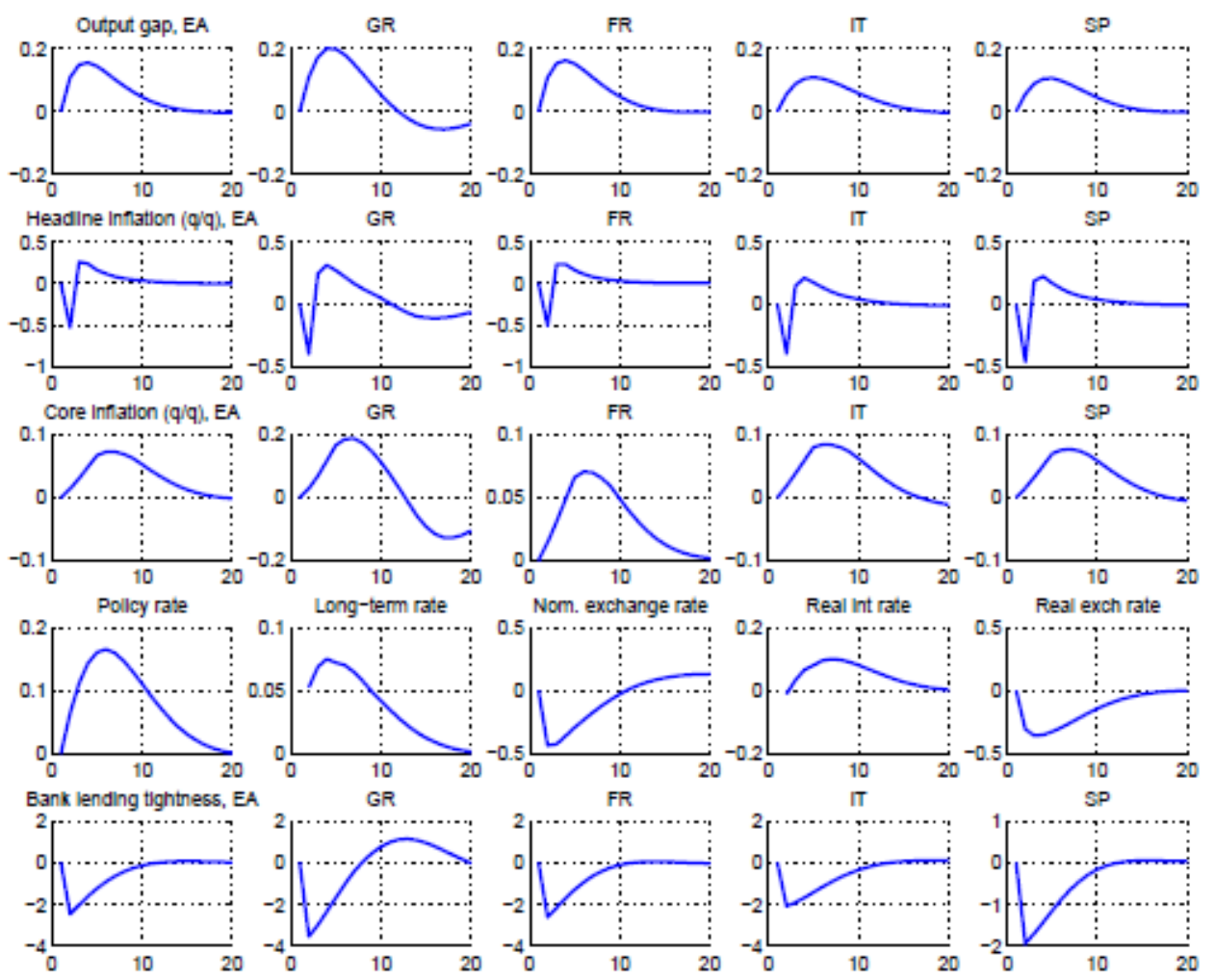


\section{Appendix III. : Euro area forecasts from the EA4 GPM}

Figure A10: Euro area forecasts from the EA4 GPM *
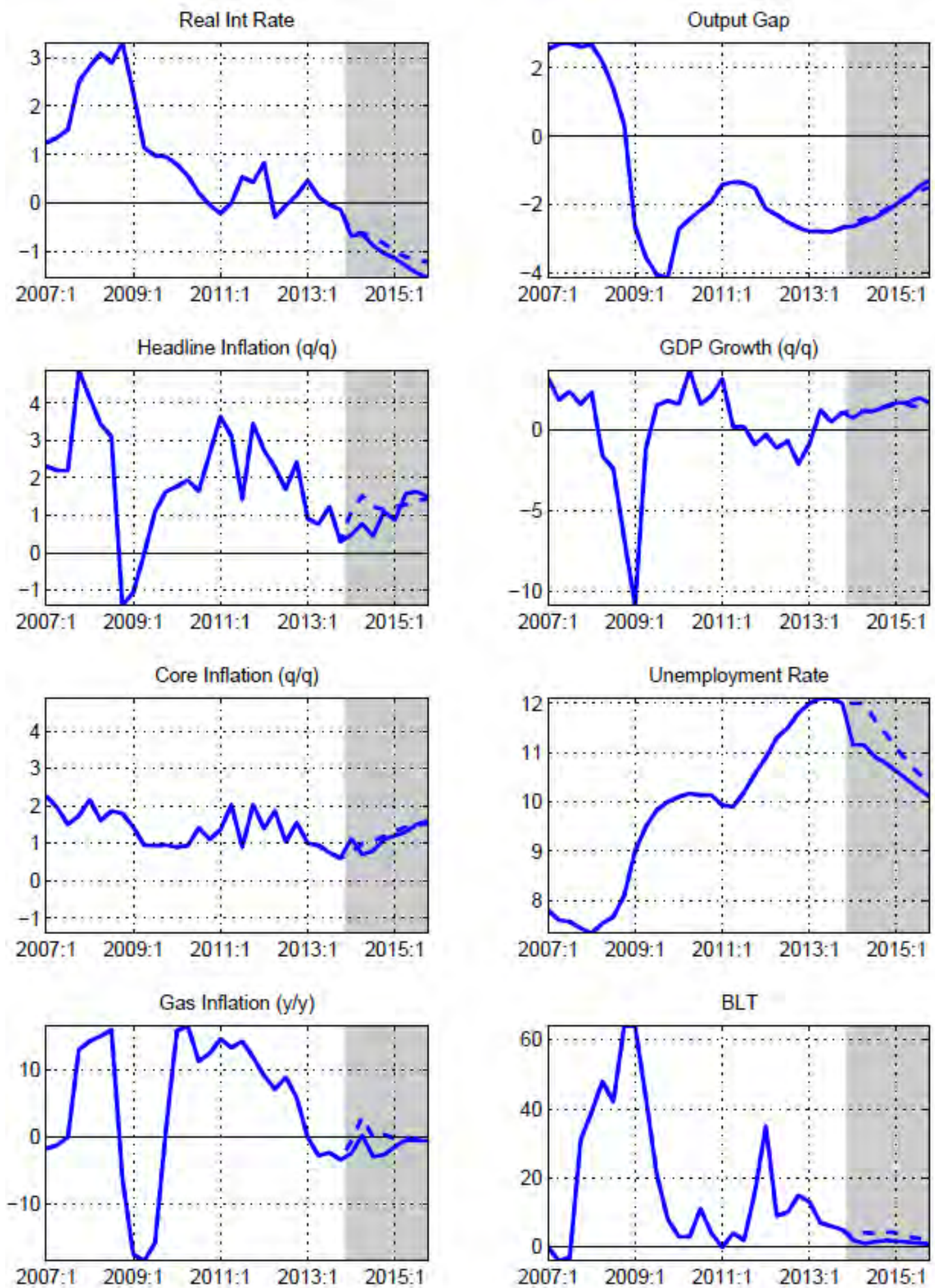

* Dashed line represents the vintage forecast of the previous WEO round in Q4 2013.

Sources: IMF staff estimates. 


\section{Appendix IV: Modified Notation in Country Blocks of the EA4 GPM}

To obtain country-specific equations for output gaps, equation (1) is replaced by:

$$
\begin{aligned}
& y_{i, t}=\beta_{i, 1} y_{i, t-1}+\beta_{i, 2} y_{i, t+1}-\beta_{i, 3}\left(R R_{t-1}-\overline{R R}_{t-1}\right)-\beta_{i, 4} \frac{\Sigma_{i=t-1}^{t-4}\left(R E E R_{i}-\overline{R E E R}_{i}\right)}{4}+ \\
& \Omega_{i, t}+\theta_{i, t}+\beta_{i, 5} \kappa_{-} \text {oil } l_{t}+\beta_{6} \kappa_{-} \text {food }_{t}+\beta_{i, \text { fact_res }_{-}} f_{a c t}^{y y}+\beta_{i, f a c t} \epsilon_{i, t}^{y}
\end{aligned}
$$

Where $f a c t_{i, t}^{y y}=\sum_{j} \varpi_{j, i} \varepsilon_{j, t}^{y y}$, and $\varpi_{j, i}$ denotes the spillover coefficient from country $\mathrm{j}$ to country i.

Furthermore, equation (2) is replaced by:

(A2) $\pi_{i, t}^{x}=\lambda_{i, 1 x} \pi_{i, t+4}^{x}+\left(1-\lambda_{i, 1 x}\right) \pi_{i, t-1}^{x}+\lambda_{i, 2 x} y_{i, t-1}+\frac{\lambda_{i, 3 x} \Sigma_{j=t-1}^{t-4}\left(R E E R_{i, j}-\overline{R E E R}_{i, j}\right)}{4}+$ $\lambda_{i, 4 x}\left(\pi 4_{i, t}-\pi 4_{i, t}^{x}\right)+\varepsilon_{i, t}^{\pi}$

Where $\pi_{i, t}^{x}$ denotes quarter-on-quarter core inflation, and $\pi 4_{i, t}^{x}$ and $\pi 4_{i, t}$ denote year-on-year core and headline inflation, respectively. 


\section{Appendix V. Calibration of Spillover Coefficients}

Following Blagrave and others (2013), the spillover coefficients in the EA GPM is calibrated in following steps. First, the effect of a demand shock in country $j$ (the shock emitter) on output in country $i$ (the shock receiver) can be written as:

$$
\Delta Y_{i}=\omega \Delta Y_{j}
$$

Where the parameter $\omega$ is the spillover coefficient, e.g., any change in the growth rate of

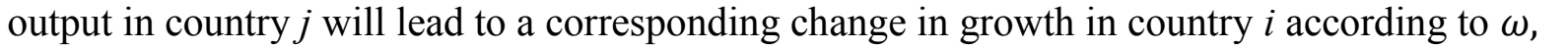

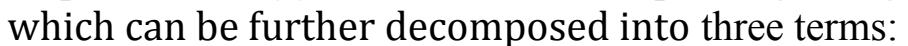

$$
\omega=\frac{\Delta Y_{i}}{\Delta X_{i j}} * \frac{\Delta X_{i j}}{\Delta M_{j i}} * \frac{\Delta M_{j i}}{\Delta Y_{j}}
$$

Where the last term denotes the change in the growth of imports by country $j$ from country $i$, for a given shock to demand growth in country $j$; and the middle term represents the change in country $i$ 's export growth to country $j$, for a given change in import demand growth by country $j$ from country $i$; and the first term denotes the change in output growth in country $i$, for a given change in country $i$ 's export growth to country $j$.

Each of these terms can be transformed as the following:

(i) $\frac{\Delta Y_{i}}{\Delta X_{i j}}=\frac{\Delta Y_{i}}{\Delta X_{i}} * \frac{\Delta X_{i}}{\Delta X_{i j}}$

(ii) $\frac{\Delta X_{i j}}{\Delta M_{j i}}=1 \quad$ by assumption

(iii) $\frac{\Delta M_{j i}}{\Delta Y_{j}}=\frac{\Delta M_{j}}{\Delta Y_{j}} * \frac{\Delta M_{j i}}{\Delta M_{j}}$

Starting with Eq. (iii), it involves two calculations: the elasticity of imports by country $j$ in response to a given change in demand growth $\left(\frac{\Delta M_{j}}{\Delta Y_{j}}\right)$; and, the relationship between the change in total import-demand growth in country $j$, and import-demand growth from country $i\left(\frac{\Delta M_{j i}}{\Delta M_{j}}\right)$. Regarding the latter calculation, we assume that all changes in import-demand growth are distributed uniformly across all trade partners. As for the elasticity of imports for a given change in demand growth, they are derived from the results of simple VAR analysis.

Next, Eq. (i) involves determining the impact of a change in the growth rate of country $i$ 's exports to country $j$ on country $i$ 's GDP growth. Starting with the second element of Eq.(i), we scale the size of the increase in exports from $i$ to $j$ in order to express it in terms of total 


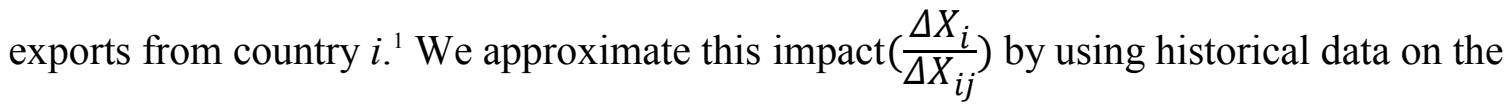
ratio of exports from $i$ to $j$ as a share of total exports from $i$.

Finally, the first term of Eq. (i), $\left(\frac{\Delta Y_{i}}{\Delta X_{i}}\right)$, is a Keynesian-type multiplier, relating the change in the growth rate of total exports from $i$ to the change in the growth rate of output in country $i$.

\footnotetext{
${ }^{1}$ A given $\mathrm{x}$ percent increase in the growth rate of exports from country $i$ to country $j$ will correspond to a smaller increase in country $i$ 's total exports (in growth-rate space). As an example, if country $i$ 's exports to country $\mathrm{j}$ increase by 10 percent, and country $i$ 's imports to country $j$ represent 50 percent of its total exports, then total exports have only increased by 5 percent.
} 